\title{
HILGARDIA
}

A Journal of Agricultural Science Published by the California Agricultural Experiment Station

CONTENTS

\section{RECENT CONTRIBUTIONS OF INSECT PHYSIOLOGY TO INSECT TOXICOLOGY AND CONTROL}

W. M. HOSKINS 


\section{$\begin{array}{lllllllll}H & \text { I } & \text { L } & G & A & R & D & \text { I } & \text { A }\end{array}$}

A Journal of Agricultural Science Published by

the California Agricultural Experiment Station

\begin{tabular}{lll}
\hline VoL. 13 & AUGUST, 1940 & No. 6 \\
\hline
\end{tabular}

\section{RECENT CONTRIBUTIONS OF INSECT PHYSIOLOGY TO INSECT TOXICOLOGY AND CONTROL ${ }^{1}$}

W. M. HOSKINS ${ }^{2}$

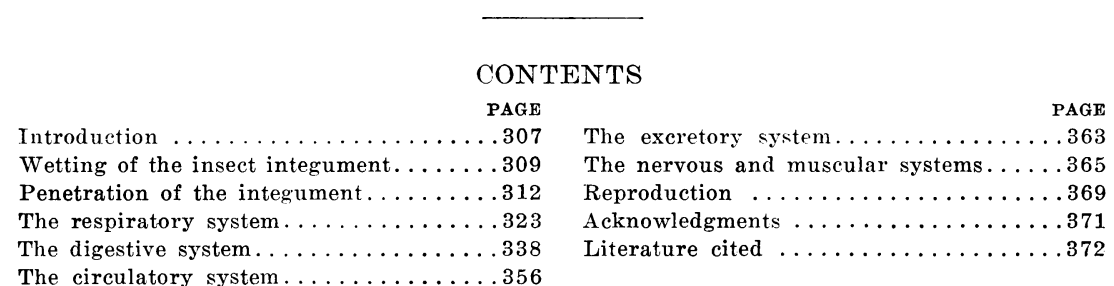

INTRODUCTION

THE INCREASING DIFFICULTY encountered in recent years in controlling insect pests has led to a searching inquiry into the conditions under which insecticides act, and the chemical, physical, and biological factors which govern their effects. Among these factors none are more important than the physiological processes which occur in the species whose control is desired. Thus insect physiology has an economic importance which makes its active development much more imperative than if it were of purely scientific interest alone. Nevertheless, few attempts have been made to apply the increasing knowledge of physiology to the problems of insect-pest control, and the accounts of such work are widely scattered in the biological literature. These conditions have made it seem worth while to attempt to interpret certain advances in this field in terms of their relations to insect toxicology and control. In general, the discussion will be limited to work done within the last few years, and important earlier contributions will be noted only in certain cases, in which it is

${ }^{1}$ Received for publication June 13, 1939 ; revised to cover the literature to January, 1940 :

${ }_{2}$ Associate Professor of Entomology and Associate Entomologist in the Experiment Station. 
necessary to develop the proper historical background. This will explain the absence of many outstanding papers which would normally be included in a historical account of the subject.

The relations of insect physiology and toxicology may be classified, in general, into two groups : (1) those concerned with the natural physiological conditions or processes which favor or oppose the action of a toxic material ; and (2) those having to do with abnormal conditions or processes resulting from the introduction of a poisonous substance into the body. The first group may make possible predictions concerning toxicity and provide a basis for understanding variations in susceptibility among different kinds of insects. The second group aims at interpretation of toxic action in physiological terms. In both cases, comparisons and contrasts may be made of different orders, families, genera, or even species of insects.

It seems logical to follow, as far as possible, the ordinary classification of physiological systems-digestive, respiratory, etc.-although in many instances emphasis must be laid on such general phenomena as permeability, distribution between various constituents of the body, and general cellular metabolism. With the ordinary methods of applying insecticides, entrance of a toxic substance into the insect body must occur through one or more of the three surfaces which together enclose the organism. These are: (1) the outer covering of the body, including the portions associated with sensory organs, external mouth parts, gills, eyes, wings, legs, etc.; (2) the lining of the various parts of the digestive tract; and (3) the lining of the respiratory system. The customary classification of insecticides into contact, stomach, and respiratory, is of importance primarily in relation to the surface through which entrance occurs. The structure and function and hence the ease of wetting and the permeability of different regions differ enormously and have a very great influence upon the effect of toxic substances. For convenience, the behavior of the outer covering of the body, that is, the integument, will be considered first and that of the other surfaces will be considered in connection with the physiological systems to which they belong.

\section{WETTING OF THE INSECT INTEGUMENT}

The ability of sprays to wet the integument often determines their toxic effects. A truly enormous amount of work has been done in the last few years in an effort to elucidate the mechanism of wetting and to classify both liquids and solid surfaces on that basis. For such a purpose, a detailed knowledge of the structure and components of insect integument is essential, but unfortunately, comparatively little progress has been 
made in this direction. The very outermost part of the integument, that is, the part which comes in contact with materials applied to an insect, is a very thin layer free from chitin but containing lipoids whose precise nature is still undetermined. The presence of these fatty substances largely accounts for the difficulty with which most insects are wet. The names "Grenzlamelle," "epicuticula," and "epicuticle" have been applied to this layer. It is soluble in strong alkali but is resistant to mineral acids except powerful oxidizing agents such as hot, concentrated nitric acid.

Kühnelt $(1928 a, b)^{3}$ concluded from a chemical examination of the wings and body integument of insects representing several orders, that sterol esters of fatty acids comprised at least a part of the lipoid material. Wigglesworth $(1933 b, 1934)$ found that the epicuticle of the bug Rhodnius prolixus is not a protein, carbohydrate, or simple fat, but probably a complex fatty or waxy substance for which he proposed the name "cuticulin." As a result of an elaborate chemical fractionation of the skin cast at the end of the last instar by the silkworm, Bombyx mori, Bergmann (1938) found the material extracted by ether or chloroform (approximately the same as Wigglesworth's cuticulin) to consist chiefly of a series of paraffin hydrocarbons and esters but to be free of sterols. His results actually indicated a hydrocarbon with the formula $\mathrm{C}_{27} \mathrm{H}_{56}$ or $\mathrm{C}_{28} \mathrm{H}_{58}$ and an ester giving the acid $\mathrm{C}_{28} \mathrm{H}_{58} \mathrm{O}_{2}$, octacosanic acid. But because of the assertion of Chibnall, et al. (1934) that insect and plant waxes contain paraffins of the odd-carbon series only and alcohols and fatty acids of the even-carbon series only, Bergmann concluded that he had obtained a mixture of hydrocarbons containing from 27 to 31 carbon atoms and a mixture of esters from alcohols and acids containing from 26 to 30 carbon atoms each.

While it is likely that a continuous layer of cuticulin covers most of the body, in many species there occur regions covered by a deposit of dried secretion from glands of the integument, the so-called "Sekretschicht" (Stegemann, 1930). Extensive masses of waxy material cover part of the body in the case of many aphids and mealybugs and an extreme example of the formation of a protective covering is afforded by the female armored scales. It is apparent that no one substance controls the ease of wetting of insects, and great differences may be expected to occur among various forms.

Hydrophobic hairs and surfaces have long attracted attention in connection with the respiration of aquatic insects ; the drowning of anophe-

\footnotetext{
${ }^{3}$ See "Literature Cited" at the end of this paper for full data on citations, which are referred to in the text by author and date of publication.
} 
line mosquito larvae in soap solution, for example, is due to wetting of their spiracles by the solution (Hacker, 1925). Data on the behavior of liquids applied to the integument of land forms are very meager. A tremendous number of observations are on record in which experimenters state their impressions as to whether wetting was good, medium, or poor, but this kind of information can be used only for qualitative comparisons. The quantitative information available is most readily expressed in terms of the angle of contact of drops of liquid applied to the surface. If no wetting occurs, the drops remain approximately spherical and the angle of contact approaches $180^{\circ}$; maximum wetting corresponds to zero angle of contact; and any intermediate ease of wetting is expressible in terms of some angle between these extremes.

The mathematical basis for the use of the angle of contact as a measure of wetting lies in the expression :

$$
\gamma_{s}=\gamma_{s l}+\gamma_{l} \cos \theta_{e q}
$$

in which $\gamma$ signifies surface energy (usually expressed as surface tension), the subscripts $s, l$, and $s l$ refer to the solid, the liquid, and the interface between these two, respectively, and $\theta_{e q}$ is the angle of contact of the liquid upon the solid. Since the equation refers only to a condition of equilibrium, a drop of liquid no matter how placed upon the surface will change its shape and area of contact until the angle of contact attains the necessary value to satisfy the relation. Wetting agents usually reduced both $\gamma_{l}$ and $\gamma_{s l}$ and hence reduce the magnitude of $\theta_{e q}$. The extension of a liquid beyond the region to which it is applied, the process of "spreading," has attracted much attention in connection with the penetration of oil into the tracheae of various insects and will be discussed in connection with the respiratory system. It is also of importance with other contact insecticides and fungicides. The best quantitative rating of spreading power available at present is the advancing angle of contact (Hoskins and Ben-Amotz, 1938). From the physiological standpoint, advances in understanding of both wetting and spreading depend on the acquisition of more data on the constitution and behavior of the insect integument.

Data on the wetting of several insects are given in table 1 . As is pointed out by the authors quoted, it is difficult to determine the angle which a liquid makes on an insect's integument when the latter gives rise to numerous hairs, bristles, or other protuberances. Data for other concentrations of the various solutions are given by O'Kane, Westgate, and Glover, but they are confusing, for wetting shows no uniform change with variations in concentration. In general, the data indicate that so- 


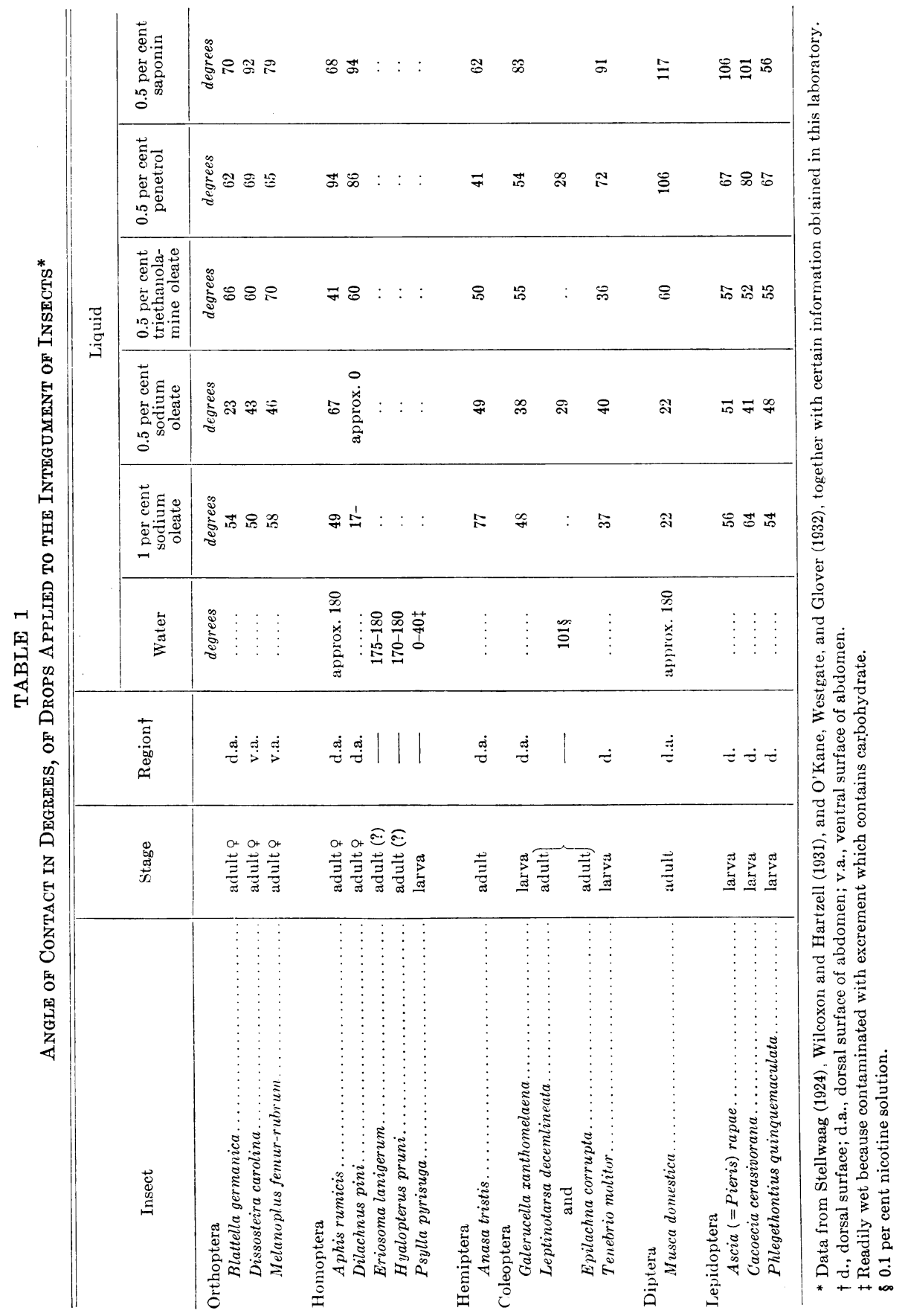


dium oleate is a better wetting agent for the insects studied than the other compounds, and saponin is the poorest. The most desirable degree of wetting is not known but probably is short of completeness, for when a liquid wets a surface very well, only a little of it will remain (Evans and Martin, 1935; Hoskins and Ben-Amotz, 1938). On the other hand, when the angle of contact is very high, the drops of liquid are likely to roll off if the insect moves or if the object on which it is located is agitated by the wind or in some other way.

When it is considered that the effectiveness of all contact poisons depends upon the behavior of the spray liquid upon the body of the pest concerned, one can only wonder that more attention has not been given to this matter in the case of mealybugs, scales, thrips, mites, slugs, etc. A very fertile field for investigation is awaiting development.

\section{PENETRATION OF THE INTEGUMENT}

After a spray has wet the integument of an insect, the next question is whether its toxic ingredient is able to penetrate through the outer covering and reach some vital part of the body. The greatest differences exist between various regions.

The idea formerly rather common among entomologists that chitin is rigid and impermeable must be abandoned, for Campbell (1929) showed by use of improved solubility and color tests that there is no relation in the case of the American cockroach, Periplaneta americana, between the occurrence of chitin and either hardness or pigmentation. Tauber (1934) corroborates this conclusion in the case of another cockroach, $P$. fuliginosa. The purest chitin so far found among insects, in the anal gills of mosquito larvae (Wigglesworth, 1933a) and the peritrophic membranes in the digestive tracts of many insects, is flexible and freely permeable to water and to many dissolved substances, as will be discussed later. This permeability is, of course, due in part to their extreme thinness.

On the other hand, the general impermeability of the insect integument was attributed by Wigglesworth $(1939$, p. 21$)$ to the extremely thin lipoid-containing epicuticle. In conformity with this hypothesis, Buchmann's (1931) observation that the relative toxicities to mosquito larvae of a series of acids are in the same order as their solubilities in lipoids is explainable if a membrane composed of or permeated by lipoids controls their entrance into the insect's body. In general, it is true that substances-such as nicotine, cyanide, or pyrethrum-which are soluble in fats or fat solvents have a more rapid action when applied to the integument than is shown by insecticides-such as arsenicals or fluo- 
rides-which are insoluble in the same solvents. Without attempting to estimate its role quantitatively, the fatty epicuticle may be safely said to play an important part in determining the ease of entrance of all contact insecticides, and for this additional reason more information on its nature and distribution is greatly needed.

In the thicker parts of the integument of insects, the inner layers undoubtedly offer a resistance to the entrance of substances which pass through the epicuticle; Klinger (1936), for example, has shown that several species of larvae all having thick cuticle are more resistant to pyrethrum than another thin-skinned group. In this connection, the vexed question of the function, or even the reality, of the pore canals through the endocuticle is of primary importance. If, as Wigglesworth (1939, p. 17) maintains, they are real tubes filled with liquid, they offer a ready means for penetration of the relatively thick endo- and exocuticle. This question affords another example of the service which may be given to insect toxicology by the physiologist and anatomist.

The available information on the penetration of toxic substances through the integument has been gained in most instances by placing the substance somewhere on the body of a given species of insect and noting the signs of distress and the mortality that ensue. Such experiments usually give only qualitative data on the rate of entry of the poison. Mention will be made below of a very few cases in which the integument, either as a unit or after separation into layers, has been used in more or less quantitative studies of permeability.

For many years the toxic effects often noted when so-called "stomach" insecticides are dusted on insects have been attributed to ingestion of some of the material during the cleaning of legs and antennae which many insects accomplish by pulling the appendages across the mouth parts. Sodium arsenite has been used for a long time in dips and baths for control of ticks, lice, and other external parasites on domestic animals. The relative importance of absorption of arsenic through the cuticle of the parasite and ingestion of arsenic which had penetrated into the skin of the host has been debated by numerous writers. Aside from this example, the first definite suggestion that an arsenical may act as a contact poison seems to have been made by Mally (1923), who dusted locusts in South Africa with sodium arsenite and found that death sometimes occurred within $1 / 2$ hour. Granovsky (1926) found in laboratory experiment that either dusts or solutions of sodium arsenite applied so they could not reach the insect's mouth nevertheless caused death in a short time. He also noted corroded areas on the bodies of grasshoppers which had come in contact with arsenical baits. Nymphs dusted during 
molting became paralyzed or deformed and upon dissection no food could be found in the digestive tract. Parfentjev (1928) has given additional proof of the contact action of sodium arsenite by experiments with cockroaches which were fitted with collars so that either dust or solution applied to the abdomen could not reach the mouth. He has also given similar data from the extensive field use of sodium arsenite by the Russians for the control of locusts. Similarly, sodium arsenate dusts applied to the bodies of Mormon crickets, Anabrus simplex, fitted with collars resulted in their death almost as rapidly as when they were allowed to clean themselves ad lib. (Hastings and Pepper, 1939). Application of small volumes of sodium arsenite solution to the antennae, eyes, palpi, and other parts of the body of nymphal locusts, Schistocerea paranensis, resulted in their death (Ministerio de Agricultura, Argentina, 1936, p. 239-48) but if application was made just before molting occurred, the mortality was low. When wireworms, Limonius canus, are confined with corn-starch pellets containing arsenic compounds or are submerged in solutions of soluble arsenicals, the digestive tract and tracheae remain relatively free from arsenic but the body fluid becomes increasingly rich in that element as the exposure continues (Woodworth, 1938). Hence the integument is assumed to be permeable to arsenic.

A conclusion at variance with that of the workers just mentioned was reached by King and Rutledge (1932) and King (1934) who found that locusts flying through a cloud of sodium arsenite dust take enough arsenic into the tracheae to account for the subsequent toxicity. The question was reëxamined by A. G. Hamilton (1937), who showed that during 10 seconds, which is the usual time required for a locust to fly through a cloud of dust as applied in the field, the amount entering the spiracles is far below the lethal quantity. Since his tests were made with cuprous cyanide instead of sodium arsenite (to simplify detection in the tracheae), there is a possibility that differences in the electrostatic charge upon the two dusts may make it impossible to reason from one to the other. However, Hamilton states that he has other data not yet published which prove the toxicity of sodium arsenite and other substances as contact insecticides. Lepesme (1937a) applied arsenical dusts to locusts and found particles of the dusts only in parts of the respiratory system immediately adjoining the spiracles.

The application of arsenious oxide confined in little beeswax cells to the dorsal metathorax of the American cockroach, Periplaneta americana, was found by O'Kane and Glover (1935) to result in arsenic becoming distributed throughout the bodies of the insects. In a further study by the same technique they found (O'Kane and Glover, 1936) 
that increasing the area to which the poison was applied increased the amount absorbed but that increasing the amount of dry powder in the wax cells had no significant effect. When arsenious oxide was used, the amount of arsenic in the whole body reached an equilibrium after 120 hours or less at about $0.025 \mathrm{mg} \mathrm{As}_{2} \mathrm{O}_{3}$ per gram of body weight; but with sodium arsenite, the amount reached $0.103 \mathrm{mg} \mathrm{As}_{2} \mathrm{O}_{3}$ per gram of body weight in 120 hours and $0.162 \mathrm{mg} \mathrm{As}_{2} \mathrm{O}_{3}$ in 168 hours and apparently was still increasing. This was thought to indicate that the insect can eliminate a low intake of arsenic as fast as it enters but is unable to handle larger amounts. O'Kane and Glover noted that the sodium arsenite in the beeswax cells absorbed enough water to entirely liquefy it within 7 days whereas the arsenious oxide only became damp. Since the wax cells were tightly capped, this moisture must have been absorbed from the cockroaches. This taking up of water by the arsenicals undoubtedly is essential for penetration of the integument, for no means are known by which solids could diffuse through such a complicated covering. This also accounts for the observation of Lepesme (1937a) and others before him that the effect of sodium arsenite dust as a contact poison is very dependent upon atmospheric humidity.

The much larger amounts of arsenic recovered from the bodies when sodium arsenite was used led O'Kane and Glover to conclude that it penetrates the integument much more freely than arsenious oxide. While this undoubtedly is true in one sense, the conclusion is apt to convey a very false impression, for the substances should be compared at equal concentrations in solution. This has been done by placing mosquito pupae in solutions of sodium arsenite adjusted to acidic and basic conditions (Hoskins, 1932), which is equivalent to comparing equally concentrated solutions of arsenious oxide and of sodium arsenite. Over the range $0.01 M$ to $0.03 M$ concentration, the dissolved arsenious oxide, that is, arsenious acid, was found to be about four and one-half times as rapid in its toxic action as the sodium arsenite, and presumably the two substances penetrated into the mosquito pupae in approximately that ratio.

The interpretation of these results was based on the theory that undissociated molecules such as those of weak acids or bases penetrate membranes faster than the ions of strong electrolytes such as the typical metallic salts. This has been illustrated by abundant data obtained with other organisms (for summaries see Osterhout, 1933; Osterhout, Kamerling, and Stanley, 1934; Ellisor and Richardson, 1938), but definite proof in the case of the insect integument was given by Alexandrov (1934, 1935) and by Morozov (1935).

Alexandrov used the aquatic dipterous larvae of Chironomus plumo- 
sus, Glyptotendipes polytomus, and Corethra plumicornis. He squeezed out the body contents and filled the little sack formed by the integument with a solution of the desired indicator. By suspending the integument from both ends so that it hung in a bow, any desired portion could be dipped into a solution of the substance whose penetration was to be studied. The integument acted as a semipermeable membrane and allowed acetic acid or ammonia to pass through it very much more readily than hydrochloric acid or sodium hydroxide. Likewise, the undissociated compounds ethyl alcohol and mercuric chloride penetrated freely. When the integument was boiled in concentrated alkali, the selective permeability was destroyed and all substances tried penetrated readily. Since such treatment saponifies most lipoids, this is an excellent indication that the lipoid-containing epicuticle is the seat of the selective action and of the general high resistance to penetration. Marked differences between the species were found, and Alexandrov suggests that the lower permeability of the integument of Corethra plumicornis enables that organism to survive in waters filled with decomposing vegetable matter and other debris which are quickly toxic to most larvae.

The same type of experiments was carried out with the same results by Morozov (1935) with lepidopterous larvae (Lotostye sticticalis, Pieris rapae, Pieris brassicae, Pyrausta nubilalis, and Eristalis arbustorum). He found also that boiling the cuticle in water for $1 / 2$ hour increased its permeability without destroying the selective action. The observation of Klinger (1936) that treatment of the cuticula of several kinds of larvae with chloroform increased the penetration of alkali is another indication of the importance of the lipoid constituents of the integument.

The effect of the $\mathrm{pH}$ of the liquid in which a toxic substance is placed calls attention to the importance of acquiring information about the $\mathrm{pH}$ and the dissolved substances present in the film of moisture which is found on the bodies of many insects. O'Kane and Glover (1935) mentioned that the cockroach, Blatta germanica, is covered with a film of liquid and that it is more abundant on males. They also found that solutions of the common wetting agents have a lower angle of contact on male integument.

It was suggested by Shafer (1915) many years ago that soluble fluoride is absorbed through the thin portions of the cockroach's integument. A study by Hockenyos (1933) is particularly valuable because it shows clearly the great differences in ease of entrance at various regions of the body. Sodium fluoride was applied to American cockroaches held in a special strait jacket which kept any part of the body from reaching the mouth. No injury resulted from dipping the antennae into a satu- 
rated solution nor from keeping a paste of the material on the antennae for 12 hours. A fine dust of sodium fluoride kept on the last three abdominal segments for the same period had no harmful effect, but a small amount of the powder placed behind the metacoxae killed or paralyzed the treated individuals in 12 hours. An application between the legs killed all in 24 hours. High mortality resulted from dusting the powder onto the ventral surface of the abdomen but the same treatment applied to the dorsal surface had little effect even when the spiracles were well covered.

In a further study of the effects of dusts upon the American cockroach, Hockenyos (1939) made the surprising discovery that the addition of finely divided lime to sodium fluoride powder greatly shortens the time before which paralysis ensues. This is contrary to what may be expected from the fact that all calcium compounds tend to react with sodium fluoride to form the very insoluble calcium fluoride. The same hastening of toxic action was observed if the lime was dusted onto the insects first, allowed to remain for 10 minutes, and then carefully removed with dilute hydrochloric acid before the sodium fluoride was applied. However, the time for paralysis to develop (in 8 out of 10 insects) increased from 10 minutes when the fluoride was applied as soon as the cockroaches were dry, to 50 minutes when application was delayed 1 hour; that is, the effect of the lime treatment wears off rapidly. Since application of oleic acid or hydrophobic powders such as aluminum stearate diminished the effect from subsequent dusting with sodium fluoride, Hockenyos concluded that the synergistic effect of the lime may be explained by assuming that it reacts with a water-repellent substance occurring upon the integument of the cockroach's body. While Hockenyos did not prove the existence of such a protective material, he suggested that the work of Ramsey (1935) on the rate of evaporation of water from the American cockroach, establishes the reality of such a fatty substance.

The foregoing account of development in knowledge concerning the nature of the insect cuticle and the penetration of inorganic toxic substances through it, has been given in considerable detail, for certain contributions of physiology to insect toxicology and gaps in information that still exist have been illustrated thereby. A brief account will suffice for the penetration and contact action of other toxic substances. The time-honored use of nicotine for control of aphids and other soft-bodied, sucking insects is an obvious indication of its ability to penetrate into the bodies of such insects, but this ability is not limited to such forms. Portier (1930) dipped the tips of the antennae of the butterflies Vanessa atalanta or Satyrus actea into solutions of pure nicotine and observed 
symptoms of distress to appear in 2 to 5 minutes. From the length of the antennae and the duration of the latent period, he calculated that the poison moved along the antennae at the rate of about 1 meter an hour. Similar symptoms, but slower in onset, followed application of nicotine to the wings. Application to the wing leads to toxic symptoms and death, however, only when the wing is of the lepidopteran type, that is, contains circulating blood in wide areas (Guignon, 1936).

As a result of a detailed study of the effects following application of nicotine to various parts of the body of the common meal worm, Tenebrio molitor, and of several cockroaches, O'Kane, Walker, Guy, and Smith (1933) found the antennae of the meal worms to be very sensitive to nicotine, but no symptoms were noted with the cockroaches unless application was made within the first fifteen or twenty segments. In general, the thin, membranous regions were more readily penetrated than the heavier portions of the integument. An interesting observation was that whenever application was made to the dorsal cervical region of fourthinstar Periplaneta nymphs, the body swelled enormously. When pricked under water, bubbles of air emerged.

The previously cited examples of penetration of nicotine have been from solutions, but this is not essential. When the abdomen (with spiracles sealed) of corn-earworm larvae, a single posterior leg of the redlegged grasshopper, or a portion of the anterior wing of the American cockroach was exposed to gaseous nicotine, pyridine, or piperidine, these substances soon appeared in all parts of the body (Richardson, Glover and Ellisor, 1934). It may be noted that the results with the wing are in agreement with Guignon's idea, for there is an active circulation of blood in the anterior wing of Periplaneta americana. A final point concerning the penetration of nicotine and other amines through insect cuticle may be mentioned as a result of the work of Richardson and Shepard (1930), who determined the time mosquito larvae must be left in solutions of the toxic substances having a definite $\mathrm{pH}$, in order to cause 50 per cent mortality. They found that basic solutions are much more rapid in their action than acidic solutions and attributed this result to readier penetration of the nicotine molecule as contrasted with that of its ion. The rate of toxicity, however, did not change nearly so fast as the proportion of molecular nicotine in the solutions, and the authors attributed the lack of agreement in the main to swallowing of some of the solutions with consequent effects of nicotine as a stomach poison. This work was repeated in this laboratory with mosquito pupae by Bliss. ${ }^{4}$ Since these

\footnotetext{
${ }^{4}$ Bliss, A. H. Toxicity studies of nicotine and nicotine-copper complex to mosquito larvae and pupae. Thesis for the degree of Master of Science, University of California, 1934. ('Typewritten.) Copy on file in the University of California Library, Berkeley.
} 
pupae have no mouth opening, ingestion is impossible and, as expected, the toxicity at different $\mathrm{pH}$ values was directly proportional to the concentration of nicotine molecules.

An interesting observation has been made on the action of anabasine, which is isomeric with nicotine, toward larvae of the butterfly Pieris brassicae, and of the sawfly, Pteronus ribesii (Ivanova, 1936). The outer layers of the integument are penetrated by liquids fairly readily, but the hypodermal layer in its normal condition is penetrated with difficulty. After exposure to 0.5 per cent anabasine solution, however, the selective action of the hypodermal cells is greatly diminished and penetration of various substances occurs much more readily.

It is probably to be expected that the marked solubility of the pyrethrins in oils will allow them to penetrate the insect integument readily. Wilcoxon and Hartzell (1933) applied pyrethrum extract in petroleum ether colored with a red dye to the dorsal surface of meal worms and, judging from the extent of penetration of the dye, decided that the pyrethins penetrated through the articular membranes around the setae and thence into the trichogen cells and the hypodermal cells. They suggested that penetration also occurs through other thin membranes, for example, between the body segments. A correlation between intensity of staining of the integument by fat-soluble dyes and sensitivity to pyrethrum was found by Klinger (1936) in a study of several larvae. The silkworm is especially sensitive. Also, contact of the integument with oleic acid increased the rate of penetration of alkali.

O'Kane, Walker, Guy, and Smith (1933) found that the intersegmental regions of the thorax or abdomen of meal worms and cockroaches were more sensitive than scleritized regions to pyrethrin extracts. Application of minute drops of pyrethrin concentrate to a rear leg or to a tarsus of the rose chafer, Macrodactylus subspinosus, led to distress and death (Hartzell and Wilcoxson, 1932). On the other hand, Hockenyos (1936) applied pyrethrum dust to the legs or to the antennae of cockroaches and allowed them to pull these appendages through their mouths. The roaches gave evidence of intense discomfort but were normal in 12 hours. Thorough dusting of all the spiracles, but not of the rest of the body surface, caused excitement and some paralysis but no mortality. A histological effect of pyrethrum-powder suspension upon the integument of Corethra plumicornis larvae was noted by F. Krüger (1931). After at least a day's contact, the hypodermal cells become loosened and vacuoles appeared.

A study by Buchmann (1933) on the condition of the pyrethrins in an aqueous extract is of interest in connection with their penetration of 
insect cuticle. He passed such extracts through graded filters and concluded that the active ingredients are not in true solution but exist as droplets or on particles whose size is between 0.005 and $0.010 \mu$. This work explains why earlier authors were in disagreement regarding the solubility of the insecticidal substance. If these minute particles or droplets maintained their identity during penetration of the integument, it would be necessary to conclude that the latter contained holes and acted like a sieve. But the probability is that as a droplet makes contact with the fatty epicuticle, it spreads into a film and thereafter penetrates as single molecules.

It has been shown in the case of a few insects that the toxic constituents of derris are able to penetrate the intact integument. Tischler (1935) applied either a dust or an extract to silkworms in such a way that none entered the mouth or the spiracles and found that toxic symptoms developed. Likewise, cockroaches whose mouths were closed were affected when they were exposed to derris dust. Application of derrisroot dust or powdered rotenone to the antennae of locusts, body segments of the gypsy moth, or legs of bees and wasps did not cause any toxic symptoms (Klinger, 1936). While but few detailed data are available, there is no doubt that the toxic ingredients of derris root have more difficulty in penetrating insect cuticle than pyrethrin or nicotine does. To some extent, the slow toxicity of derris may be due to this condition.

The emphasis laid by numerous writers on the lipoid layer of the insect integument as the chief cause of impermeability would suggest that oils should enter readily. Attention has been directed usually, however, to penetration by way of the spiracles. There are serious difficulties in detecting the minute amounts of oil concerned and in distinguishing between natural oil in the body and that from outside. Klinger (1936) used the integument of several species of insects as a membrane between water and an oil emulsion and observed after a time that oil accumulated on the water side. Many studies have been made to determine the action of oil applied to scale insects, usually however, from the standpoint of penetration of the tracheal system. Ebeling (1936) by direct observation has found that oil from a small drop placed on one side of the armor of the California red scale, Aonidiella aurantii, often reaches the other side within a few minutes. The armor is a complex mixture of shed integument and waxy and nonwaxy secretions. It covers the insect both above and below except for small openings; hence, ease of penetration may be a very important property of any substance used for control of this or any other armored scale. In an experiment very similar to that just mentioned, O'Kane and Conklin (1930) found that lime-sulfur solution does not penetrate the covering of the San Jose scale, Aspidiotus perniciosus. 
Studies on the constituents and the chemical nature of the covering of armored scales have been very fragmentary. About 10 per cent of the dry weight of the oyster-shell scale, Lepidosaphes ulmi, and of the California red scale is soluble in ether (Metcalf and Hockenyos, 1930; Haas, 1934) and hence may be considered to be lipoids of one kind or another. Carbon tetrachloride extracts $30-40$ per cent of the total weight of dried oyster-shell scale, of the Florida red scale, Chrysomphalum aonidum, and of the pine leaf scale, Chionaspis pinifoliae; but this substance is not a specific solvent for lipoid material. Beran (1939) separated the covering of the San Jose seale from the body of the insect and determined the amounts extracted by 24 hours' exposure to 10 per cent emulsions of fruit-tree carbolineum and of petroleum spray oil. At $22^{\circ} \mathrm{C}$, the decreases in weight were 12.8 per cent and 17.2 per cent, respectively. At $2^{\circ} \mathrm{C}$ they were 0.6 per cent and 6.97 per cent. The high solubility in mineral oil, even at the low temperature, is undoubtedly related to the wellknown scalicidal effects of oil sprays. A number of the unarmored scales occurring in Japan have been examined chemically by Kono (19321933) and Kono and Maruyama (1934-1938). Numerous waxes and fatty acids have been found, but no correlation with the behavior or effects of insecticides has been attempted.

The very common use of oil as an ovicide has given rise to several theories regarding its toxic action, such as interference with respiration of the developing embryo, hardening of the shell or other membranes so as to prevent hatching, interference with water balance, entrance into the inner regions and coagulation of protoplasm or interference with hormone or enzyme action. The precise mechanism doubtless varies with different eggs, but evidence has accumulated to prove that oil can penetrate into the interior of the eggs of several insects. The structure of the outer layer of certain eggs, at least, is very complex. Jahn (1935b) examined the diapause egg of the grasshopper, Melanoplus differentialis, and found the secreted membranes to be of two kinds, (1) the exo- and endochorions, which are formed by the mother; and (2) the cuticle and cuticular layer, which are secreted by the serosa cells of the egg after development starts. The two layers of the chorion give tests for protein, but the thin, yellow cuticle strongly resembles the cuticulin on the outer surface of insects. It is waxy and highly resistant to wetting by water. The cuticular layer is similar to but perhaps not identical with chitin. The shell of silkworm eggs contains 5.7 per cent of a waxlike material (Ongaro, 1933), which is considered by Bergmann (1938) to be a mixture of odd-numbered hydrocarbons. While the evidence for a lipoid 
layer in the outer parts of insect eggs is scanty, is offers a reasonable explanation for the penetration of oils and fat-soluble substances.

Fox, ${ }^{5}$ using eggs of the leaf roller, Archips argyrospila, in oils saturated with Sudan III or oil red $O$ found faint red coloring in the interior of the eggs. By sectioning cockroach and grasshopper eggs exposed for several hours to an oil of $80^{\circ}-85^{\circ}$ Saybolt viscosity, O'Kane and Baker (1934) were able to trace the oil into the chorion and as streaks penetrating along the body folds of the developing embryo. In a further study (O'Kane and Baker, 1935), they found the same oil to penetrate the eggs of the snowy tree cricket (Orthoptera), Mexican bean beetle (Coleoptera), squash bug (Hemiptera), pine leaf aphid (Homoptera), lacewing (Neuroptera), and cecropia moth (Lepidoptera). Powers and Headlee (1939) deny that petroleum oils can penetrate the eggs of the mosquito, Aedes aegypti, and attribute the ovicidal action entirely to suffocation.

Many substances other than oils are effective ovicides, and direct toxic action upon the embryo is indicated in some cases. An illustration is afforded by the tar oils and various phenolic derivatives which have been widely used for control of aphids by spraying the eggs during the winter (Staniland, Tutin, and Walton, 1930; L. M. Smith, 1937). These eggs can survive heavy applications of petroleum oil and hence are resistant to smothering action. The nature of the toxic action of tar oils and of dinitrophenol and other such compounds upon aphid eggs deserves careful study.

It has long been known that insect eggs are able to absorb or lose water in accordance with the surrounding humidity. Dissolved substances, however, often cannot penetrate; for example, Jahn (1935a) found the diapause eggs of the grasshopper, Melanoplus differentialis, to be impermeable to potassium ferrocyanide and ferric chloride. Slifer (1938) has found a region on the surface of the grasshopper egg which is readily permeable to water and accordingly has been called the "hydropyle." When it was covered with an impermeable layer of liquid solder, respiration of the egg was normal (which proves that oxygen and carbon dioxide penetrate the general surface readily) but the customary increase in weight did not occur and development was almost entirely stopped. If the solder was removed after four weeks, development was resumed. While no data are available on the point, these results of Slifer suggest that the effects of certain ovicides, such as lime-sulfur, may be due to destructive changes which they cause in the permeable regions of insect eggs.

\footnotetext{
${ }^{5}$ Fox, R. H. The action of certain oils on the egg-masses of the leaf roller, Archips argyrospila Walk. Thesis for the degree of Master of Science, University of New Hampshire, 1930.
} 


\section{THE RESPIRATORY SYSTEM}

The physiological function of any respiratory system requires that it be freely permeable to oxygen and carbon dioxide, and usually to water. Permeability, however, is never a strictly specific matter, and many other substances, including some of a poisonous nature, find their way into the living body via this route. These substances are not necessarily gases, for liquids and finely divided solids may enter at least the outer parts of the respiratory system and inhibit normal gaseous exchange, or injure the tissues they encounter directly, or by vaporizing may reach and injure deeper parts of the tracheal system, or may have an effect upon any other tissue of the body after penetrating the tracheal membranes and getting into the circulatory system. Information concerning the chemical constitution of the various parts of the respiratory system, their wettability and readiness of penetration by gases and dissolved substances, is obviously essential for an understanding of the action of respiratory poisons.

When water is applied to the integument of an insect in the region of a spiracle, it does not ordinarily pass through the spiracle and enter the tracheae beneath. The same resistance to penetration of the tracheae by water occurs with aquatic insects whose external body surface is entirely bathed by water. On the other hand, oils readily enter into the tracheae although the spiracular valves of some insects are able to exclude them fairly well. Thus there is a strong resemblance between the wetting characteristics of insect integument and of the lining of the tracheae, for the entrance of a liquid into a tube is governed by the generalized relation that controls spreading over a plane surface, that is,

$$
\stackrel{<}{\gamma_{\mathrm{s}}} \underset{>}{>} \gamma_{\mathrm{s} 1}+\gamma_{1} \cos \theta
$$

The symbols have the same meaning as in equation 1 (p. 310), which is the form assumed when an equilibrium extension is reached by a limited volume of liquid, except that $\theta$ is the angle of contact at any given time rather than at equilibrium. In the filling of a tube, the essential change is replacement of solid-gas interface by solid-liquid interface and hence the energy available per unit area of interface is

$$
\Delta \gamma=\gamma_{\mathrm{s}}-\gamma_{\mathrm{s} 1}=\gamma_{1} \cos \theta
$$

By simple calculation it may be shown (Hoskins, 1933) that for a cir- 
cular tube of radius $r$, the available energy per unit of cross-sectional area, that is, the capillary pressure, is

$$
\epsilon=\frac{2 \gamma_{1} \cos \theta}{r}
$$

The magnitude of the available energy is obviously dependent upon the value of the angle of contact, $\theta$; for example, if $\theta=0^{\circ}, \epsilon=\frac{2 \gamma_{1}}{r}$; if $\theta=90^{\circ}, \epsilon=\frac{2 \gamma_{1}}{r} .0=0$; if $\theta=180^{\circ}, \epsilon=\frac{-2 \gamma_{1}}{r}$. Whenever $\epsilon$ is negative, the significance is, of course, that energy of the indicated magnitude will be required in order to force the liquid into the tube, and if the pressure is released the liquid will withdraw again. Whenever $\theta$ is less than $90^{\circ}$, with excess liquid there is no theoretical limit to the distance it will penetrate a tube such as a trachea, except that pressure of confined gas or other liquid within the tube may become great enough to balance the capillary pressure. When a liquid rises vertically, the hydrostatic head becomes a limiting factor, but this is seldom important in the case of insect tracheae because of their short length. Certain authors have used the ordinary formula for the height of ascension in a tube,

$$
h=\frac{2 \gamma \cos \theta}{d r g}
$$

( $d$ stands for density, $g$ for acceleration due to gravity; other symbols as in previous equations), and have interpreted $h$ as the total distance along the tracheae, regardless of whether this was vertical, horizontal, or inclined. Such usage is entirely invalid.

The rate of entrance may vary greatly, for it is a function not only of the surface tension and angle of contact but also of the viscosity of the entering liquid and of the distance already penetrated. The observation has often been made that light oils such as kerosene enter the spiracles and tracheae of insects much faster than do heavier oils.

If the spray liquid or its toxic ingredient is readily volatile, as is a light oil or a nicotine solution, or if adsorbing material such as dry bark is near, the rate of entry into the respiratory system is a very important factor in the insecticidal effect. Equation 4 shows that the smaller the tube the greater the capillary pressure. This relation probably accounts for the fact that insects are often able to expel liquids which have entered only into the larger tracheae but cannot do so when penetration has proceeded farther. As might be expected, the less viscous liquids, for example, light oil (deOng, Knight, and Chamberlin, 1927) are expelled more readily than viscous liquids. The speed of movement along the 
tracheae is directly proportional to the diameter of the tube (Hoskins, 1933) and, accordingly, even very light oils require considerable time, sometimes many hours, to reach into the minute tracheoles. This slowing down in rate of entry doubtless accounts for the conclusion of some workers that penetration had stopped after a very short time; for example, O'Kane, Westgate, Glover, and Lowry (1930) noticed no movement of aqueous solutions of soaps and nicotine into the tracheae of larvae of Tenebrio molitor and Pieris rapae after 3 minutes.

The data on entrance of various spray liquids are numerous and often inconsistent, but it may suffice to state by way of summary that among the materials ordinarily added to aqueous sprays to increase their wetting power, soap is most effective in promoting entrance into the tracheal system. The contact angle of 0.5 per cent sodium oleate solution in the tracheae of the tomato worm is $85^{\circ}$ (Wilcoxon and Hartzell, 1931), so the capillary pressure is very low. The jerky manner in which liquids progress along tracheae has often been noted, especially during wriggling of the insect, and it has been attributed to contraction or relaxation of the air tubes and air sacs. This point is related to the question of whether inspiration in insects is an active or a passive process. The interesting suggestion has been made by Ebeling (1936) that very sudden flow of oil along a tracheal tube may indicate rupture of the delicate walls of a tracheole so that pressure of gas within it is suddenly released. This idea is consistent with the observation that globules of oil are often noted in the muscles and body cavity after exposure of the insect to an oil spray.

An important instance of the entrance of oil into the tracheal system is afforded by the use of oil to kill mosquito larvae and pupae. The small size and thin integument of these insects suggests that respiration is not entirely dependent upon the respiratory system. This is illustrated by the results of Ramsay and Carpenter (1932) who found Anopheles and Culex larvae to die in less than 20 minutes when confined in a bottle completely filled with air-free water but to live up to 45 hours under the same arrangement when the water was not deaerated.

It was pointed out by Corbett and Hodgkin (1931) that an amount of oil by no means sufficient to fill the tracheae often causes them to collapse. Murray (1936) studied this phenomenon more in detail and found that collapse of the tracheal trunks is more apt to follow exposure to volatile oils, especially those rich in aromatics and other reactive constituents. The larvae are strongly averse to rising to a surface covered with such oils and accordingly expose themselves less than when aliphatic oils are used. Tracheal collapse may be considered as a defensive mechanism, 
for such larvae live much longer than those whose tracheae become filled with oil. Hence nonreactive oils may bring about death of the insects more quickly than reactive oils. The difference may be very great, for example, a few hours as contrasted with several weeks. Murray also observed that Anopheles pupae are more easily killed than Culex pupae because the trumpets of the former are larger and easier for oil to enter.

The question of how completely the respiratory system may become filled with an oil is of special importance in connection with the idea of Wigglesworth $(1930 a)$ that the tracheoles are filled with an aqueous liquid to an extent (measured from the blind end) inversely proportional to the recent activity of the insect. A balance between the capillary tension within the tube and the osmotic pressure in the surrounding body fluid determines the extent to which the tracheoles are filled at any given time. In two recent studies, Wigglesworth $(1938 a, b)$ has shown that other factors besides these two enter into the situation, but the essential idea of a balance is still maintained. Upon fragmentary data, he calculated the magnitude of each of these quantities in the mosquito larva to be approximately 10 atmospheres. The assumption was made that the angle of contact within the tracheoles was very low. If this is true, the lining of the tracheoles must differ greatly from that of the tracheae and spiracles. On the other hand, it has been stated that oil eventually entirely fills both tracheae and tracheoles (Nelson, 1927, working with bees and meal worms; Wigglesworth, 1930a, with mosquito larvae; Ebeling, 1936, with red scale). Hence the lining of the tracheoles must possess the remarkable property of being wet strongly by both water and oil. A possible but not probably explanation of this anomaly is that the oil alters the normal surface and changes its wetting properties. The question of why and how the liquid which fills the tracheal system during embryonic life is replaced by gas at about the time of hatching (Sikes and Wigglesworth, 1931) is also related to changes in the wetting properties of the tracheal lining. If this always repelled water, it would follow that a considerable pressure existed within the egg at all times, which is contrary to the facts. It is obvious that for the needs of either embryology or toxicology, there is a great dearth of information concerning the tracheal system.

Only slight correlation between the wetting of a paraffin plate and entrance of liquids into the tracheae of the beetle, Melasoma tremulae, was found by Gäbler (1939). He applied over a score of liquids, most of which were proprietary insecticides, to limited regions of the insect, and compared the depth of penetration of the tracheal system with the time of death after total immersion. Since these two criteria were closely re- 
lated in the case of certain liquids and widely divergent in others, Gäbler concluded that contact insecticides may be divided into those which pass directly through the integument and those which act only by way of the tracheae. The application of liquids to individual spiracles of scale insects by use of a micropipette, as suggested by Smith (1938) for oil, provides a very convenient method for studying the entrance of any liquid into the respiratory system of insects whose tracheae are visible through the overlying body tissues.

The question of how seriously a toxic gas will affect an insect is very largely a matter of how readily it may enter the tracheal system of the species concerned. This is related to the manner in which aeration of the system occurs. Very inactive insects, such as scales, doubtless depend entirely upon diffusion to supply sufficient oxygen and to eliminate carbon dioxide, but active insects usually show rhythmical movements of the thorax or abdomen which alternately compress and relax the air sacs and larger tracheae. Such a process is much like the breathing of man or animals. A good example is afforded by mosquito larvae, which ventilate the whole respiratory system through a single pair of spiracles at the end of the abdomen. Most insects, however, have several pairs of tracheal openings in different parts of the body and the possibility exists that air may enter by some and leave by others, that is, directed ventilation may occur by way of the larger tubes and air sacs. In such a case, diffusion needs to proceed only within the smaller tubes; if this process continues in the presence of a toxic gas there will be opportunity for much more of it to reach the thin-walled tracheoles than would be the case if diffusion alone permitted entrance into the body.

After the work of Krogh $(1920 a, b)$, emphasis was laid on the adequacy of diffusion for respiratory needs, but the fact remains that the spiracles of many insects open and close in a cyclical manner which appears to be coördinated with rhythmical movements of the abdomen or, more rarely, of the thorax. Various methods such as observation of spiracular action, sealing certain spiracles, submerging parts of the insect, etc., have led to the conclusion that ordinarily certain spiracles are inspiratory and others expiratory, although in an emergency any spiracle can serve either or both functions. The conclusive proof of directed ventilation in certain insects has been obtained by putting the fore part of the individual in one chamber and the rear part in another so that any passage of air forward or backward in the respiratory system would be indicated by corresponding changes in volume of the two vessels. In this manner McGovran (1931, 1932) found female grasshoppers, Chortophaga viridifasciata, to inspire air through the thoracic spiracles and 
expire it by way of the abdominal spiracles at an average rate of $0.22 \mathrm{cc}$ per gram of body weight per minute when all determinations were made at $28^{\circ} \mathrm{C}$. Similar ventilation from front to rear was found with the Hawaiian cockroach, Nyctobora noctivaga (Kitchel and Hoskins, 1935), this directed flow of air being maintained, at least for short periods, against a pressure of $20 \mathrm{~cm}$ of water. This behavior demonstrates that there is very accurate correlation of respiratory movements and spiracular action.

The effect of poison gases upon the process of ventilation has been studied directly with only a few substances and few species of insects, although it has been noted many times (for example, Pratt, Swain, and Eldred, 1933) that insects are made quiescent by some substances and activated by others, and the assumption has often been made that the rate of respiration is affected similarly. McGovran (1932) found the ventilation of grasshoppers to be increased when the thorax was exposed to sublethal concentrations of carbon disulfide, hydrogen cyanide, or nicotine, but to be decreased when the concentration was higher. Somewhat different effects were observed when the Hawaiian cockroach was exposed to nicotine vapor (Kitchel and Hoskins, 1935) ; for over a wide range of concentration, the tracheal ventilation was always decreased. Observation of individual scale insects led Pratt, Swain, and Eldred (1931) to the conclusion that 0.005 per cent hydrogen cyanide caused "stupefaction" within 10 minutes, and higher concentrations much quicker.

This phenomenon of stupefaction or anesthesia of insects upon exposure to sublethal concentrations of a fumigant has assumed enormous practical importance in connection with the control of scale insects with hydrogen cyanide. Since insects so treated are harder to kill with a subsequent normal dose of gas, the term "protective stupefaction" was used by Gray and Kirkpatrick (1929) to describe the condition. In practical citrus fumigation, there is considerable leakage of gas through the tent walls, and each time a tent is lifted some residual gas inevitably drifts about neighboring trees, although the effect may be lessened by paying heed to the prevailing movement of air. Similarly during fumigation of large masses of grain or other such products, very low concentrations of gas first reach the insects which are at a distance from the point of application (Mackie and Carter, 1937). That the phenomenon actually occurs with the granary weevil, Sitophilus granarius, but not with the confused flour beetle, Tribolium confusum, or the convergent ladybird beetle, Hippodamia convergens, was proved in fumatorium experiments by Lindgren (1938). Peters (1936, p. 72) has stated that protective stupe- 
faction in the case of the granary weevil is due to cessation of mechanical ventilation so that cyanide can enter only by diffusion; but this cannot be the case with scale insects, in which a mechanical explanation of the condition must involve closing of the spiracles so that diffusion is impaired. In certain cases, at least, diminution in toxicity may be effected by mixing with the fumigant a gas which by itself is stupefying to the insect. Thus Pratt, Swain, and Eldred (1933) found that the addition of 0.1 per cent trichloroethylene or 1 per cent carbon dioxide to 0.2 per cent hydrogen cyanide caused a decrease in toxicity to convergent ladybird beetles. This result with carbon dioxide is remarkable in view of its ability to stimulate ventilation in certain insects, and serves to emphasize the necessity for more data on its effect with other insects.

In the case of scale insects, protective stupefaction has often been associated with the so-called "cyanide resistance." The idea that differences in susceptibility to a poison may arise within an insect species so that two or more distinct "strains" or "races" exist which still are morphologically identical has presented new problems to the practical control operator, the taxonomist, the toxicologist, and the physiologist. The first publication on the subject apparently was by Melander (1914), who reported that San Jose scale in Washington was becoming more resistant than formerly to lime-sulfur sprays. Two years later Quayle (1916) recorded unsatisfactory results in the fumigation of red scale, Aonidiella aurantii, in the Corona district of southern California. The condition has now become widespread in the citrus district (Quayle, 1938) and also exists among black scale, Saissetia oleae, and citricola scale, Coccus pseudomagnoliarum. It is not manifested toward cyanide alone but also with ethylene oxide and methyl bromide.

From the biological point of view, the chief interest in this problem is concerned with the examination of possible physiological factors concerned in it. Unfortunately, the data are few. Moore (1933), attracted by the idea of a difference in adsorption (see his later work with other insects-Carpenter and Moore, 1938), suggested that resistance to cyanide fumigation would develop in regions in which the scales secreted exceptionally large amounts of wax and thus interposed a mechanical barrier to penetration of the gas into the body. This possibility seems to be ruled out by the fact that the motile young red scales which have no covering show the same differences toward cyanide as do the adults (Quayle, 1938). Also, the other two scales in which resistance has been noted are unarmored. A further suggestion made by Moore (1933) was that protective stupefaction is characteristic of resistant red scale but not of the nonresistant strain. 
Pursuing this idea, a study of the different manifestations of protective stupefaction in resistant and nonresistant red scale has been made under carefully controlled laboratory conditions by Lindgren (1938). He found the resistant variety to show quickly the effect of a preliminary small dose of cyanide (maintained for 5 minutes only), that is, protective stupefaction is brought on very rapidly. It persists for 1 hour with little change but thereafter wears off and after 2 and 3 hours the insects are actually easier to kill than if no preliminary light dose had been given. The nonresistant insects show a resistance to the normal concentration of cyanide if it is not given until 1 hour after the preliminary dose. The effect persists for at least 3 hours. In other words, the difference between the two groups consists at least in part in different rates of reaction to the stupefying charge of cyanide. The resistant variety both reacts and recovers rapidly whereas the nonresistant is more sluggish in both respects. Other differences may be found when the concentration and exposure to the stupefying dose are varied. Unfortunately, no reports on these points have been issued as yet.

This difference in readiness of reaction to cyanide may be an indication of a difference in general vigor between the resistant and nonresistant strains. Quayle (1938) mentions that as long ago as 1927 certain workers thought the resistant strain to be more tolerant of oil sprays. In the analogous case of codling-moth resistance to lead arsenate, Hough (1934) found the larvae of the Colorado moth to be more proficient in entering either sprayed or unsprayed apples and to be hardier in general.

To the practical sprayman, it is of little interest whether the insects of a given species in a certain district are harder to control than those in another district because they have a difference in feeding habits, a larger amount of wax, a different spiracular action, or a genuine difference in susceptibility to the toxic substance. For an analysis of the situation into physiological factors, with the ultimate aim of finding the cause, however, it is essential to know whether the chief difference is in physical conditions, such as amount of wax, or in the intimate physiological processes of cell or tissues.

The observations of Carpenter and Moore (1938) regarding "sorption" (that is, combined absorption and adsorption) of hydrogen cyanide are interesting in this connection, for they found the order of susceptibility of rice weevil, tobacco beetle, meal worm, confused flour beetle, and German cockroach to this substance to be in the same order as the amounts held in the body after equilibrium had been established at a fixed pressure of the gas. The variation in sorption capacity is 
very great. Thus at $20^{\circ} \mathrm{C}$ and partial pressure of $\mathrm{HCN}$ of $47.5 \mathrm{~mm}$, the amounts of hydrogen cyanide held at the end of 80 minutes are (in the same order as above) $1.06,2.99,7.41,11.7$, and $13.7 \mathrm{mg}$ per gram of insect. In the case of the insects which held the larger amounts of gas, equilibrium was practically reached in 80 minutes, but both the rice weevils and tobacco beetles were still taking in cyanide at nearly the initial rate. Carpenter and Moore concluded that the differences in toxicity of hydrogen cyanide are probably small for the insects studied but that the large differences in effectiveness which occur under ordinary methods of fumigation are due to variations in readiness of sorption by the insects. Whether there are differences in the sorption capacities of resistant and nonresistant scales does not seem to have been determined.

An attempt has been made by Haas (1934) to correlate variations in resistance of red scales to hydrocyanic acid with their chemical composition, particularly reducing sugars, iron, phosphorus, manganese, and copper. Since the analyses were made on the whole dried insect with wax, shell, excrement, and dirt included, it is not surprising that great variations were found from one lot to another. Nevertheless, indications were found that low content of copper is associated with resistance to cyanide. There is no doubt that investigations of this kind, preferably made with the insect body or parts separated from other contaminating material, will throw light on many toxicological problems.

The ability of carbon dioxide to increase the rate and amplitude of respiration of man and animals has caused numerous investigators to add it to various fumigants. The results on the whole have been favorable. Cotton and Young (1929), for example, found the adults of Tribolium confusum and Sitophilus oryzae to be much more susceptible to the vapors of carbon disulfide, chloropicrin, ethylene dichloride, methyl chloroacetate or ethylene oxide when small amounts of carbon dioxide are added. Cotton (1932) determined the toxicity of chloropicrin, ethylene oxide, and carbon disulfide to Tribolium confusum adults in the presence of various concentrations of carbon dioxide and found that there is an optimum value of the latter for each toxic gas. Maximum toxicity of a mixture of methyl bromide and carbon dioxide against the red flour beetle, Tribolium castaneum, was obtained by Jones (1938) when the latter gas was present at a concentration of 10 to 40 per cent by volume. At higher concentrations a marked drop in toxicity occurred. The practice of adding carbon dioxide to ethylene oxide or ethylene dichloride has become so well established that several commercial preparations of the combined gases are in use in this country and in Europe.

Carbon dioxide was expected to increase the effectiveness of hydrogen 
cyanide also, but results have been disappointing. Cotton (1932) stated that it did not have this effect, but he gave no details concerning the concentrations nor insects used. Definite reduction in kill of ladybird beetles by 0.2 per cent hydrogen cyanide when either 1 per cent or 99.8 per cent carbon dioxide was added was reported by Pratt, Swain, and Eldred (1933). No data on intermediate concentrations were given. Two years later these same authors (Pratt, Swain, and Eldred, 1935) found that an exposure of black scale, Saissetia olcae, to carbon dioxide before the introduction of the cyanide resulted in an increase in percentage survival according to the concentration of the carbon dioxide as follows: 2 per cent carbon dioxide, 4.4 per cent increase; 5 per cent carbon dioxide, 4.2 per cent increase; and 10 per cent carbon dioxide, 7.2 per cent increase. However, if the two gases were admitted together, there was no significant change in toxicity from that with cyanide alone. A contrasting result was obtained by Cupples, Yust, and Hiley (1936) with resistant red scale. They obtained a greater kill with cyanide in the presence of 10 per cent carbon dioxide. Though in all this work, variable factors were reduced to a minimum, the results are far from clear-cut. Obviously, application to field work is not possible as yet. Analogy with Lindgren's results (1938) on the relative rates at which protective stupefaction develops in resistant and nonresistant scales suggests that a study of the speed with which insects react to carbon dioxide may throw light upon its effects as an auxiliary gas in fumigation.

Hazelhoff (1928), as a result of his work on exposing the American cockroach to various concentrations of carbon dioxide, emphasizes that the opening of the spiracles brought about by this gas ought to promote the toxic effects of various fumigants. It has been shown with the Hawaiian cockroach, however, that the spiracles do not remain open, for there is a great increase in the front-to-rear ventilation over a wide range of carbon dioxide concentration (Kitchel and Hoskins, 1935). This ventilation diminishes greatly at high concentrations of carbon dioxide because respiratory movements cease. If these same conditions hold for other insects, it would follow that the favorable effects obtained by adding carbon dioxide to fumigants are due to acceleration of respiratory movements and consequent increase in the volume of air and fumigant mechanically taken into the tracheal system, rather than to increased diffusion through wide-open spiracles. The lowest concentration of carbon dioxide used, however, was 5 per cent, and accordingly there is no contradiction between these results and the theory that the spiracles are caused to stand open by low concentrations of carbon dioxide, for example, 0.2 to 3.0 per cent (Stahn, 1928). 
More work on this important point should be done with other insects. In particular, more information is needed on the nervous control of spiracular action and respiratory movements and the influence of chemicals on them. It has been postulated by Stahn (1928) that the responses of the walking-stick insect, Dixippus morosus, to the presence of carbon dioxide or to lack of oxygen are governed by two independent nervous centers. The primary group, located in each segment, is relatively insensitive; whereas the secondary one, located in the prothorax, responds much more readily. This theory seems contradictory to Hazelhoff's idea (1928) that low concentrations of carbon dioxide cause the spiracles to open, and higher concentrations induce respiratory movements, for if both theories are true it would follow that the spiracles are controlled by a nerve center in the prothorax and respiratory movements by the several segmental centers. The opposite situation seems much more probable.

Aside from marked advantages in distribution of the toxic material, the theory and practice of vacuum fumigation are based upon the idea that the respiration of insects is increased by diminution in the concentration of oxygen, with consequent wider opening of the spiracles or more energetic respiratory movements, or both. Such an increase in respiration with diminishing pressure is, of course, characteristic of man and animals, at least for moderate reductions from normal pressure.

The relative importance of total pressure and of oxygen pressure is not yet entirely clear, for Cotton, Wagner, and Young (1937) found the kill of Tribolium confusum with ethylene oxide to be much greater when the pressure of residual air was $2 \frac{1}{2}$ inches than when practically pure oxygen was present at this same pressure. On the other hand, Moore and Carpenter (1938) determined that addition of nitrogen and consequent increase in total pressure decreased the toxicity of hydrogen cyanide to the same insect.

In the construction and operation of chambers for vacuum fumigation, much effort is usually made to secure and hold as high a vacuum as possible, on the theory that insect kill is thereby favored. In general, this assumption is true, but an important exception has recently been reported by Moore and Carpenter (1938): the rice weevil, Sitophilus oryzae, is increasingly susceptible to hydrogen cyanide as the total pressure drops until at a pressure of about $60 \mathrm{~mm}$ of mercury, maximum kill is obtained. Thereafter, the susceptibility steadily and rapidly decreases down to the lowest pressure tried, that is, 1-2 mms of mercury. At this very low pressure, the insects are entirely quiescent, whereas they are active at $60-\mathrm{mm}$ pressure. It is logical to attribute the drop in kill under 
the high vacuum to the insects' feeble respiration. However, the confused flour beetle, Tribolium confusum, is equally quiescent, but its susceptibility is at a maximum at this same low pressure. Moore and Carpenter were able to show that active rice weevils at $60-\mathrm{mm}$ pressure "sorb" several times as much cyanide as do inactive weevils at either 60or 2-mm pressure. In contrast to this behavior, activity does not affect the amount of cyanide taken up by the confused flour beetle. Evidently the rice weevil has some means for excluding cyanide even when completely quiescent. These results are parallel to those reported by Carpenter and Moore (1938) on the relation of toxicity and sorption of cyanide by several other insects.

The rate of metabolism and consequently the respiratory activity are affected very greatly by temperature, for example, lepidopterous larvae (Raffy, 1934) and grasshoppers (Koidsumi, 1935), and the determination of how this factor alters the effects of fumigants is of both theoretical and practical interest. It is commonly understood by entomologists that susceptibility increases as temperature rises, and for many insects this rule is valid: Lindgren (1935), for example, found the dosage of either carbon disulfide or of chloropicrin required for 50 per cent kill of Tribolium confusum to drop steadily as the temperature was changed from $10^{\circ}$ to $35^{\circ} \mathrm{C}$; and Cotton (1932) obtained similar results with ethylene oxide. Below about $10^{\circ}$, however, the situation alters and an increased susceptibility at lower temperatures is often encountered: Peters and Ganter (1935), for example, call attention to the decrease in concentration of cyanide needed to give complete kill of $T$. confusum at $0^{\circ}$ as contrasted with $10^{\circ}$. This condition is not characteristic of cyanide alone but is also found with chloropicrin, carbon disulfide, ethylene dichloride, and possibly with carbon tetrachloride (Shepard, Lindgren, and Thomas, 1937). On the other hand, the toxicity of ethylene oxide decreases very markedly at low temperatures (Peters, 1936, p. 71). A comparison of the toxicities of methyl bromide to T. confusum and to Sitophilus granarius shows the former to be most resistant at about $10^{\circ}$, but the resistance of the latter insect suddenly increases below this temperature and relatively enormous concentrations are needed at $0^{\circ}$ (Shepard and Buzicky, 1939).

The red scale, Aonidiella aurantii, provides the best example of the intricate relations between temperature and susceptibility to a fumigant. It is pointed out by Moore (1933) that the resistant strain is harder to kill with cyanide at high temperatures, whereas the nonresistant strain is but slightly affected by changes in conditions. In a later paper (Moore, 1936), he reports that, for the same exposure, from 30 
to 35 per cent more hydrogen cyanide is taken up by red scales at $20^{\circ} \mathrm{C}$ than at $30^{\circ}$, but does not clearly state whether this applies to both strains or only to the resistant one.

A valuable study of the effects of temperature and humidity upon cyanide fumigation has been made by Quayle and Rohrbaugh (1934). When lemons infested with red scale were kept at $50^{\circ}, 75^{\circ}$, or $90^{\circ} \mathrm{F}$ for four hours or longer before fumigating at room temperature in a metal fumatorium (so that loss of gas was at a minimum), the highest mortality was always secured with the insects preconditioned at $50^{\circ}$, and in most cases those held at $75^{\circ}$ were more susceptible than the $90^{\circ}$ group. If the preconditioning period was shorter than 4 hours, the differences in kill were less marked. A further lowering of temperature to $35^{\circ} \mathrm{re}-$ sulted in only slightly higher kill than was secured at $50^{\circ}$. In contrast to Moore's results, Quayle and Rohrbaugh found no difference between resistant and nonresistant scales. Low humidity favors increased kill if other conditions are equal, but between 50 and 89 per cent relative humidity, no significant effect was found. By way of contrast to the results with red scale, Knight (1925) found that under gastight conditions the black scale is harder to kill at low temperatures.

The foregoing discussion will doubtless give the impression that considerable data have been acquired on the variation in mortality in fumigations carried out under different conditions, but that interpretation in physiological terms lags far behind empirical information. This condition is due to the general lack of understanding of the physiological details of insect life, but, in particular, there is need for experimental work on the respiration of scale insects. The difficulties are obvious, but with the aid of modern apparatus and methods of analysis there is no reason to doubt that they can be overcome.

The consumption of oxygen and production of carbon dioxide by the individual cells and tissues are, of course, the final steps of the respiratory process. Both the absolute amounts of the gases and their ratio are of importance. Insects are characterized by the ability to respire anaerobically for prolonged periods, during which time the oxidative steps are largely lacking. Hence an "oxygen debt" is incurred and extraordinary amounts of carbon dioxide are produced when oxygen is again available. The ability of insects to utilize oxygen from very dilute concentrations doubtless explains their resistance to suffocation. Thus Cook (1932) found that nymphs of the termite, Termopsis nevadensis, are able to respire almost normally until the oxygen concentration falls to about 2 per cent and even a stay of 2 days in 0.8 per cent leads to no appreciable oxygen debt. The red scale also is resistant to oxygen lack, for Ebeling 
(1936) found that 50 per cent mortality did not occur until after 10 hours' exposure to air treated with hot copper, which is a very efficient method for removing even the last traces of oxygen.

Only a beginning has been made in studying the effects of poisons upon insect-tissue respiration. Fink (1926) found that when larvae of Japanese beetles, garden wireworms, or adult potato beetles are given arsenicals by mouth, the oxygen consumption is lessened and the respiratory quotient, $\frac{\left(\mathrm{CO}_{2}\right)}{\mathrm{O}_{2}}$, is raised. On the basis of the relative amounts in various insects of one of the enzymes concerned in cellular oxidation, glutathione, he suggests (Fink, 1927) that the fundamental action of arsenic is interference with some step of the oxidative process. Parfentjev and Devrient (1930) injected 0.05 ce of soluble arsenite solution into the coxae of a rear leg of the American cockroach and determined the total respiration and the respiratory quotient for several hours. The lethal dose for individuals weighing about 1.2 grams each was determined to be $0.1 \mathrm{mg} \mathrm{As} \mathrm{O}_{2}$. The average oxygen consumption per gram of body weight was, before injection, 0.69 ec; 1 hour after injection, $0.68 \mathrm{cc} ; 2$ hours after injection, 0.61 cc. The enormous dose of $5 \mathrm{mg}$, which rendered the insects apparently lifeless within a very few minutes, resulted in the following oxygen consumptions in a typical case : before injection, 0.53 cc; 1 hour after injection, $0.22 ; 4$ hours after injection, 0.16 cc. The respiratory quotient 2 hours after the 5 -mg dose was 0.81 , which is but little different from the 0.75 value for the normal cockroaches. The oxygen consumption of individual organs was determined before and after immersion in various concentrations of arsenic solutions, with the following results (expressed as percentage reduction) : (a) mid-gut, $1: 200$, 75 per cent; $1: 5,000,54$ per cent ; $1: 10,000,0$ per cent; $(b)$ coxal muscle, $1: 1,000,38$ per cent. Since the lethal dose ( $0.1 \mathrm{mg}$ in $1.2 \mathrm{gms})$ is about $1: 12,000$, death from arsenic obviously cannot ordinarily be due to reduction in tissue respiration. Skrjabina (1936a) determined the rate of tissue respiration of the fifth-instar nymphs or larvae of Locusta migratoria, Pieris brassicae, and Euxoa segetum by the rate of reduction of methylene blue and further found that this rate was reduced 50 per cent in each insect by the same amount of sodium arsenite. The minimum lethal dose of this same compound varies from 0.03 to $0.135 \mathrm{mg}$ per gram of body weight. Hence the variations in resistance to arsenic are not the result of differences in the effect upon tissue respiration.

The work of Tischler (1935) showed that derris has a marked effect upon insect respiration. Injection of an extract into grasshoppers, silkworms, or corn-ear worms caused almost immediate cessation of respi- 
ratory movements and spiracular action. Oxygen consumption of the grasshopper soon dropped to 42 per cent of normal. Tischler was unable to find any other effects of derris serious enough to account for its toxicity and concluded that its primary effects are upon respiration. This agrees with the fact that death from derris is slow, for insects are much more tolerant of disturbances in the mechanical part of respiration than other animals. Haag (1931) found that animals given rotenone in various ways underwent a preliminary stimulation of respiratory action, followed by depression and failure.

Parfentjev and Devrient (1930) injected solutions containing 0.08 $\mathrm{mg}$ of potassium cyanide into cockroaches. Almost immediately the insects became apparently dead, but respiration continued for several hours with little change from that of the living insects. In fact, the respiration of insects killed by hurling on the floor was about the same as those poisoned by cyanide. Accordingly it may be concluded that death was not due to respiratory failure.

Of the two ways in which carbon monoxide interferes with the respiration of animals, that is, formation of a very stable compound with hemoglobin and inhibition of an enzyme concerned in tissue respiration (Keilin, 1929) only the latter applies to insects. Very few quantitative data are available, but Wolsky (1938) has found that carbon monoxide inhibits the respiration of Drosophila melanogaster pupae in proportion to its concentration, that is, Warburg's (1927) formula is obeyed: $\frac{n}{1-n} \cdot \frac{\mathrm{CO}}{\mathrm{O}_{2}}=K$, in which $n$ is the fraction of the total normal respiration which persists in any given atmosphere of carbon monoxide. In general, however, the effects of this gas are not serious enough to make it a practical fumigant.

The most comprehensive investigation on the effects of various chemicals upon cellular respiration in insects is that which Bodine has been carrying on for several years with grasshopper embryos. Details of that work are not appropriate here, but it may be mentioned that he has shown (Bodine, 1934; Bodine and Boell, 1934) the respiration of these embryos when developing to consist of a cyanide- and carbon-monoxidesensitive and a cyanide- and carbon-monoxide-resistant fraction; during diapause only the resistant fraction is carried out. Further detailed studies on this and other features of respiration are needed on many insects at various stages in order to bring the available information on insect respiration to a level comparable with that on mammalian respiration. 


\section{THE DIGESTIVE SYSTEM}

A stomach poison is nearly always swallowed along with the food to which it has been added and hence will be subjected to the conditions prevailing during the digestive process. It is to be expected that the manner and severity of the toxic action will be dependent upon the chemical substances which occur in the fluids of the digestive tract. Among these none is more important than the hydrogen-ion concentration, usually expressed for convenience in the terms of $\mathrm{pH}$. In the first place, the solubility of most insecticides is determined by the $\mathrm{pH}$ value. Furthermore, those which are salts of weak acids or bases, such as all the arsenical or nicotine compounds, are decomposed to give the undissociated acid or base to an extent determined by the $\mathrm{pH}$ of the liquid in which they occur. It has been pointed out previously in discussing contact insecticides that molecules penetrate through membranes more readily than ions. Hence entrance of the toxic substance into the tissues of the digestive tract or into the body fluid is influenced by the $\mathrm{pH}$ within the various digestive organs.

The buffering power, that is, the ability to maintain a constant $\mathrm{pH}$, may be an important property, for ingested material often contains acids or bases or they are liberated by bacterial action and will tend to alter the $\mathrm{pH}$ of the digestive fluids. Decomposition of a stomach poison may occur as a result of a replacement reaction to form a new compound, as when lead arsenate plus soluble phosphate gives lead phosphate and soluble arsenate. Hence it is important to have information concerning all substances in the food or in the digestive juices. Determinations made on the digestive tract as a whole are of comparatively little use, for conditions differ in various parts and even in different regions of the mid-gut in some insects, such as blowfly larvae, Lucilia sericata (Hobson, 1931), and tsetse fly, Glossina spp. (Wigglesworth, 1929).

As in every other phase of insect physiology, the available information is fragmentary and based on only a few kinds of insects. Since the general anatomical features of the digestive tract are covered in numerous textbooks and the physiological characteristics have been discussed in reviews (Uvarov, 1928; Wigglesworth, 1939; Hoskins and Craig, 1935), the present discussion will be limited to cases in which the toxic effects of various stomach poisons are affected by conditions within the digestive tract or in which the structure or function of the digestive organs are altered by the toxic substance.

The first body fluid with which an ingested substance comes in contact is the saliva, except with those insects which have no salivary glands. 
Analyses of insect saliva are very scanty but they suffice to show that there are marked differences in $\mathrm{pH}$, enzymes, and other properties between various species. In some instances these properties are very important, for example, the irritation from the bite of certain bloodsucking insects is largely due to anticoagulins and other substances in the saliva, as was indicated by the work of Lester and Lloyd (1928) with the tsetse fly. After removal of the salivary glands, the bite of these insects caused no reaction in the most sensitive skin, but coagulation of ingested blood in the proboscis and crop ultimately led to the death of the flies. Other bloodsuckers, such as mosquitos and gnats, also secrete an irritating substance before or while taking a meal (deBuck, 1937). It is obvious that this seemingly trivial circumstance is largely responsible for the effort which is made to control such insects. Another illustration is afforded by the work of Fife (1932) and Fife and Frampton (1936), who found that the salivary fluid of the beet leafhopper, Eutettix tenellus, is very alkaline and that the mouth parts are sensitive to the $\mathrm{pH}$ of the liquid in plant tissues. There is a gradient in $\mathrm{pH}$ of a beet leaf from the epidermis to the phloem, and regardless of how the mouth parts are first inserted they follow this gradient of increasing $\mathrm{pH}$ and are led almost unfailingly to the alkaline phloem. Transmission of the virus of curly-top disease from insect to plant requires that the virus reach the phloem. Thus the alkalinity of the saliva and the sensitivity of the mouth parts of the beet leafhopper to acid are fundamental factors in the spread of a very serious plant disease.

Other illustrations of a similar nature might be mentioned, but no data showing an effect of insect saliva upon toxicity of an insecticide seem to have been recorded; probably saliva plays a part only when a sucking insect, such as a fly, applies saliva to a solid poison, which would otherwise be incapable of ingestion, and then sucks in the dissolved or suspended material. As has frequently been noticed, insects which do not have biting mouth parts nevertheless are injured by solid insecticides. This has been attributed to absorption into the plant sap and subsequent ingestion by the insect or to direct penetration through the cuticle as has been discussed earlier, or to ingestion during licking or rubbing of the appendages with the mouth parts. Solvent action by the saliva is undoubtedly of importance in the case of any insect which grooms itself or its companions, and investigation of the solubility of the more important stomach poisons in the saliva of such insects would be very much worth while.

The fore-gut assumes many forms in the various insect orders but appears never to have digestive secretions of its own nor to play an im- 
portant role as an absorptive organ. In those insects which have large fore-guts, such as the Orthoptera and Hymenoptera, the action of the saliva of course continues, often for a long time. And in this case, the mid-gut secretion may move forward into the fore-gut and initiate typical mid-gut digestion, as was shown by H. S. Swingle (1925) to occur in the cockroach. The fore-gut, however, does not display any behavior which is of much importance with ingested poisons.

The insect mid-gut is the region for secretion of digestive juices and absorption of the products of their action. Hence it corresponds rather closely in function to the stomach and small intestine of vertebrates. There is general agreement that this is the chief site for absorption of ingested insecticides, though experimental proof is scanty. Nenjukov and Tareev (1928) analyzed the fore-, mid-, and hind-guts of locusts and of cockroaches which had been fed arsenical baits and found most arsenic in the tissues of the mid-gut, less in those of the hind-gut, and very little in the fore-gut. They obtained similar results when the digestive tracts from healthy individuals were kept in solutions of sodium arsenite for several hours and then analyzed for arsenic. Görnitz (1933a) found that after ingestion of calcium arsenate by Vanessa io larvae, an indented and darkened area developed on the abdomen directly below the anterior half of the mid-gut, and he concluded that this must be the region of major absorption of arsenic. In contrast to the fore- and hind-gut, the cells of the mid-gut are not covered by a permanent chitinous intima but are freely exposed. In many species, however, a peritrophic membrane of one kind or another more or less completely encloses the mass of food and, hence, digestive enzymes and products of digestion must penetrate through it. This membrane is chitinous in nature and, accordingly, is freely permeable to most substances in aqueous solution. Mention of its role in the action of stomach poisons will be made later.

Determinations of the $\mathrm{pH}$ of the insect mid-gut have given values which extend over approximately the range 3 to 10. Although numerous data have been recorded (see, for example, the summaries by M. C. Swingle, 1931a; P. Krüger, 1933; or H. S. Swingle, 1938), they are often of very uncertain reliability because of faulty technique such as the use of indicators in strongly colored liquids. The mid-gut sometimes consists of regions which have different structure and function, but $\mathrm{pH}$ determinations have seldom paid heed to this situation. Probably the best example so far noted is the larva of the blowfly, Lucilia sericata (Hobson, 1931). In the anterior portion of the mid-gut, the $\mathrm{pH}$ was found to vary from 6.5 to 7.5 ; in the middle segment from 3.0 to 3.5 , and in the poste- 
rior segment from 7.3 to 8.4. Obviously, a determination made upon the whole mid-gut of such an insect would be entirely without meaning. It is not known whether such contrasting conditions occur in many species nor what the effects of age or state of development may be.

The $\mathrm{pH}$ of the food ordinarily has but little direct effect upon the mid-gut $\mathrm{pH}$. Thus Swingle (1931b) found no difference in Japanese beetle larvae taken from soils which differed greatly in $\mathrm{pH}$. Trappman and Nitsche (1933) and Skrjabina (1936b) compared the $\mathrm{pH}$ of the juices from erushed leaves of about a dozen plants with the $\mathrm{pH}$ of the intestines of insects feeding upon them and found no correlation. The $\mathrm{pH}$ in the crop and ventriculus of newly hatched codling-moth larvae is between 8.4 and 8.7; and ingestion of relatively large amounts of apple pulp, having a $\mathrm{pH}$ of 3.3 and titratable acidity of 0.6 per cent as malic acid, does not appreciably affect the original basic condition.

Such a circumstance must be attributed to the effect of a buffer in the digestive fluid. Indirect evidence for a buffer in the intestine of the adult housefly was found by Pearson and Richardson (1933), who showed that the toxicity of arsenite by mouth is the same regardless of the $\mathrm{pH}$ of the solution containing it. Similarly, the $\mathrm{pH}$ of arsenite solutions has much less effect upon the toxicity to mosquito larvae than to mosquito pupae, presumably because the former swallow some of the liquid and bring it to a uniform $\mathrm{pH}$ in the absorbing region of the gut (Hoskins, 1932). Quantitative data on the buffering power of an insect digestive fluid has apparently been secured for only one insect, the worker honeybee (Hoskins and Harrison, 1934). In the ventricular liquid, two maximums in buffering power occur, one at $\mathrm{pH} 6.8$ due to phosphate and another at $\mathrm{pH} 4.1$ due to an unknown system, probably organic in nature. There can be but little doubt that more information on the buffer power of insect digestive fluids and its changes under the influence of poisons would be of real use in understanding the differences in susceptibility that often occur among even closely related species; for example, median lethal doses of acid lead arsenate to the larvae of the Lepidoptera Cirphis unipuntis, Vanessa cardui, and Polygonia interrogationis are 0.25, 0.16, and $0.06 \mathrm{mg}$ per gram, respectively (Hansberry and Richardson, 1936).

Among the stomach poisons whose solubility and effectiveness may be expected to vary with $\mathrm{pH}$, lead arsenate has frequently received attention. On chemical grounds it may be predicted that in either acid or basic solutions this compound will give rise to soluble arsenic, but in an intermediate range the solubility should be at a minimum. A detailed study of this subject has been made by H. S. Swingle (1938), who found that lead arsenate in potassium acetate buffers, has a minimum solu- 
bility at $\mathrm{pH} 5$, though there is comparatively little variation from $\mathrm{pH} 2$ to 7 . Between $\mathrm{pH} 7$ and 9 , however, the soluble arsenic increases to a high value, which persists in more alkaline solutions.

Calcium and magnesium arsenate are affected in exactly the opposite way, that is, they are freely soluble in acid solutions, but from $\mathrm{pH} 4$ to 6 the solubility of each drops very rapidly and in the case of the magnesium compound no more arsenic is liberated in alkaline solutions than from lead arsenate in acid solutions. The solubility of paris green diminishes from very high values in acidic solutions to a minimum at about pH 5 and then increases slightly (Lavrov and Paramonova, 1936).

These same authors have studied the effect of variation in $\mathrm{pH}$ upon the solubility of sodium fluosilicate. In the presence of acids, this substance is partially converted to the soluble hydrofluosilicic acid and in the presence of bases it is decomposed according to the equation :

$$
\mathrm{Na}_{2} \mathrm{SiF}_{6}+6 \mathrm{NaOH} \rightarrow 6 \mathrm{NaF}+\mathrm{Na}_{2} \mathrm{SiO}_{3}+3 \mathrm{H}_{2} \mathrm{O} .
$$

The total amount of fluoride in solution is a minimum at an intermediate $\mathrm{pH}$ of about 5.5, according to the results of Lavrov and Paramonova. It has been found by Carter (1931) and Nisikawa (1932) that addition of small amounts of lime to fluosilicates results in liberation of soluble fluoride. H. S. Swingle (1938) found calcium in the digestive secretions of all the insects which he tested. Whether the amounts are sufficient to set free an appreciable amount of fluoride from injested fluosilicate or cryolite has not been determined. It should also be noted that calcium in the diet may have the same effect. Since soluble calcium salts readily form the very insoluble calcium fluoride, the effects are also dependent upon the $\mathrm{pH}$ of the insect gut. It is as yet scarcely possible to decide how small amounts of lime will affect the toxicity of fluorine compounds, but much lime will invariably reduce the toxic effects.

Since the solubility of arsenicals, and of other inorganic insecticides in general, is dependent to a marked degree upon $\mathrm{pH}$, no marked correlation is to be expected between solubility in ordinary water and toxic effect. This conclusion has been verified by the results of Cook and McIndoo (1924), Fulmek (1929), and numerous others. True, acid lead arsenate is more soluble and more toxic than basic lead arsenate, but these compounds are so closely related that their solubilities under various conditions may be expected to vary in a closely parallel manner. Hence in this case determinations made in water afford an index of relative solubilities under conditions prevailing within the digestive tract (see Campbell and Lukens, 1931), but this situation does not prevail with stomach poisons in general. 
$\Lambda$ ttempts to correlate toxicity with solubility at the $\mathrm{pH}$ prevailing in the mid-gut have been partially successful. Thus Fulmek (1929) determined the solubility of all the common slightly soluble arsenites and arsenates at $\mathrm{pH} 9.0$ and found a fair agreement with their relative toxicities to the larvae of a beetle and to three caterpillars. This $\mathrm{pH}$ value is an average of the range 8.4-10.3 found in the gut of the silkworm by Shinoda (1930) and was considered as representative of plant-feeding insects by Fulmek. On the other hand, Dodonov (1936) concludes from a study involving the last nymphal instar of Locusta migratoria and the last larval instar of several lepidopterons, that the toxicity of sodium arsenite, paris green, sodium fluosilicate, or sodium fluoride is not related to the solubility of the compounds in water kept at $\mathrm{pH}$ equal to that in the mid-gut of the insects as determined by Lavrov and Paramonova (1936), that is, $\mathrm{pH} 6.85$ for L. migratoria and 9.24 to 9.69 for the others. In fact, the higher solubility in alkaline solution is associated with a lower toxicity toward the lepidopterous larvae than toward the grasshopper. Dodonov is inclined to interpret this paradoxical result to conversion of the dissociated salts to nonionized molecular acids at the lower $\mathrm{pH}$ and consequent readier penetration through the tissues of the digestive tract. Görnitz (1933b) also found the alkaline condition in the gut of several insects of the orders Lepidoptera and Coleoptera to be associated with low susceptibility to arsenicals, and he likewise attributes this to poor penetration of the poisons in the ionized state.

The kinds and concentrations of various ions and molecules, which occur within the digestive tract and consequently may influence the condition of an ingested poison, are dependent upon the food and upon the secretions of the respective regions. Very few data are available for either starved or fed insects. H. S. Swingle (1936) found phosphate in the digestive fluid of all insects which he examined. The ventricular contents of honeybees contain phosphate, all in inorganic form, at an average concentration of $0.044 M$ (Hoskins and Harrison, 1934). The mid-gut contents in the case of Lucilia sericata larvae were found by Hobson (1931) to contain phosphate, though the amount was definitely less in the posterior segment. This circumstance suggests that resorption of phosphate may occur in this insect just as it does in the honeybee. Hydrochloric acid and its salts apparently do not have the important role in insect digestion which they have in that of mammals. In fact, chloride seems to be replaced by phosphate. Consequently, any poison, such as lead arsenate, barium fluosilicate, or copper arsenite, which forms an insoluble product with phosphate, will undergo a reaction.

The effect of phosphate upon the solubility of three arsenicals has 
been studied by H. S. Swingle (1938). It has little effect on acid lead arsenate up to $\mathrm{pH} 6$ but beginning at this point much more arsenic is liberated in the presence of phosphate than in its absence. This condition is not brought about immediately, in fact, within 1 hour there is no appreciable effect; but within 5 hours it becomes very marked. Of course, such an effect of time is dependent upon the state of subdivision of the solid and the concentration of soluble phosphate, but the indication is clear that with those insects which vomit soon after ingesting arsenic, there will be but little added toxic effects on account of phosphate in the digestive tract. In contrast to the situation with lead arsenate, Swingle found that phosphate has only a slight effect upon the solubility of calcium or magnesium arsenate at any $\mathrm{pH}$. His data show that the relative toxicity of the three arsenicals to the nine species of phytophagous insects used is correlated with the relative amounts of arsenic put into solution when the arsenicals are left for prolonged periods in phosphate solutions of the $\mathrm{pH}$ which occurs in the mid-gut of the respective insects. $\Lambda$ s a matter of fact, there is nearly as good agreement between toxicity and solubility in the corresponding acetate buffers, that is, phosphate does not seem to govern the relation.

Marshall (1939) has made use of Swingle's results in interpreting the fact that lead arsenate is at least as effective as calcium arsenate in controlling codling-moth larvae, although the calcium arsenate contains one-third more arsenic and is more soluble in ordinary water. The $\mathrm{pH}$ of the digestive fluids of newly emerged codling-moth larvae is approximately 8.5, as determined from the color assumed by ingested thymol blue indicator. At this $\mathrm{pH}$, lead arsenate is more soluble than calcium arsenate and hence the latter will be acting under unfavorable conditions. Whether soluble phosphate has a role in connection with arsenicals has not been determined for the codling-moth larva, but in conformity with other lepidopterous larvae, phosphate probably is a constituent of the digestive-tract fluids.

It will be noted that the results of Swingle and of Marshall disagree with those of Dodonov (1936) (discussed on p. 343), who used several phytophagous insects with other arsenicals and two fluoride compounds; and they are not in harmony with the theory that an alkaline mid-gut insures low arsenic susceptibility. Since different stomach poisons were used, the results may not really be in conflict, and the effects of $\mathrm{pH}$ upon absorption and toxicity are doubtless more intricate than is indicated by the simple theory based upon degree of ionization.

Since toxicity is influenced very greatly by the ease with which poisons pass into and through the tissues of the digestive tract, the data on that 
point will now be examined briefly. In the mid-gut of most insects, there occurs a very thin tubular structure known as the peritrophic membrane, whose origin has been the subject of dispute centering around two theories: (1) it is the result of a secretion from all or most of the mid-gut cells which fuses into continuous sheets, sometimes showing a polyhedral structure corresponding to the shapes of the individual cells (von Dehn, 1933); (2) it is formed from the secretion of cells in the proventriculus at the junction of fore- and mid-gut, which has the form of an annular press by which the peritrophic membrane is molded as the secretion seeps through the closely adjacent rings of cells (Wigglesworth, 1930b). According to these theories, there might be several or only one membrane in the gut at a time. Abundant support has been cited for both modes of formation, and probably each occurs to some extent in many insects. Regardless of its origin, the result is that the ingestion of food stimulates the formation of a membrane through which the digestive juices, soluble constituents of the diet, and products of digestion must pass before absorption by the gut tissues proper can occur. Hence the permeability of the peritrophic membrane is an important factor in the action of stomach insecticides. Chemically speaking, the membrane appears to consist only of chitin, although in Glossina Wigglesworth (1929) obtained faint color tests for protein which he suspected of being due to adhering food. The results of Brown (1937) cast some doubt on this subject, for he found the covering, presumably the peritrophic membrane, surrounding the excretory pellets of the grasshopper, Melanoplus bivittatus, not to give the characteristic microchemical tests for chitin.

The studies which have been made with the peritrophic membrane of insects indicate that size of the diffusing molecules is the most important limitation, that is, hemoglobin passes (tsetse fly, Wigglesworth, 1929) as do the smaller dye molecules, such as methyl violet, but larger ones such as Congo red are held back (termite, Montalenti, 1932). These results are confirmed in general by von Dehn (1933), who fed solutions or suspensions of a large series of dyes to adult honeybees and bluebottle flies, Calliphora vomitoria, and after intervals of 15 minutes to 93 hours examined the peritrophic membrane and gut cells for color. Most of the dyes penetrated through the membrane to some extent, but only the very smallest colloidal ones entered the gut cells. Differences were found between the two insects, for the bee gut was more readily stained than that of the fly.

An interesting observation regarding the peritrophic membrane of the petroleum-fly larva, Psilopa petrolii, was noted by Thorpe (1930). 
The entire digestive tract of this insect is filled with petroleum, but the oil does not go through the peritrophic membrane and hence does not reach the cells of the mid-gut. This behavior is in sharp contrast with the ease with which at least the lighter fractions of petroleum oil pass through the tracheal walls once they have gotten into the air passages, and is another indication that chitin is not the most important constituent of the tracheal lining. It is not possible to decide from the scanty evidence on hand whether oil-soluble substances, such as the pyrethrins, cannot pass through the membrane. In general, the peritrophic membrane affords little protection against the ordinary inorganic insecticides. But if a difference in $\mathrm{pH}$ inside and outside the membrane, as found in the larvae of culicine mosquitoes (P. Krüger, 1933) should prove to be the case with other insects, the solubility of such insecticides as the arsenicals or fluorides would be seriously affected. This point is worth investigation. Then, too, the resistance to passage of large dye molecules indicates that other large molecules, for example, rotenone, may be held back.

In a careful study of the chitinous lining of the fore-gut of the lobster, Homarus vulgaris, Yonge (1936) showed that the chitin of this organism acts as a simple diffusion membrane, that is, solutes including electrolytes pass through it in accordance with their mobilities, and the degree of ionization is not a controlling factor. Minimum permeability occurs at $\mathrm{pH} 3.5$, which may be taken as the isoelectric point of chitin. The effects of various ions could be interpreted in general in terms of changes which they induce in the degree of hydration of the membrane.

A detailed study of the absorption of arsenic into and through the mid-gut tissues of the cutworm, Euxoa segetum, and of the immature forms of the butterfly, Pieris brassicae, and of the grasshopper, Locusta migratoria, has been reported by Voskresenskaya (1936a). The last instar before maturity was used, and the amounts of poison fed were close to the minimum lethal doses. In order to ensure that the mid-gut was empty when the poisoned food was first offered, no food was allowed for 24 to 72 hours before that. These insects differ strikingly in the periods required for food to pass through the mid-gut and through the entire digestive tract, as shown in table 2.

Thus the ingestion of arsenic results in more rapid passage of food, that is, a purgative effect, with the cutworm and the caterpillar, but in a retardation, possibly an intestinal paralysis, in the case of the grasshopper. With all three insects, a plug of poisoned food persisted for a long time in the fore-gut. For purposes of comparison, it may be noted that the normal time that food stays in the mid-gut of nymphal or adult 
$\Lambda$ merican cockroaches is not over 3 hours (Snipes and Tauber, 1937). $\Lambda t$ intervals after the poisoned food was eaten, analyses were made for the amounts of arsenic in the excrement, in the tissues of the digestive

TABLE 2

Passage of Food through Mid-gut and Entire Digestive Tract*

\begin{tabular}{|c|c|c|c|c|c|c|c|}
\hline \multirow[b]{2}{*}{ Insect } & \multirow[b]{2}{*}{$\begin{array}{c}\mathrm{pH} \text { of } \\
\text { mid-gut }\end{array}$} & \multicolumn{3}{|c|}{ Food stayed in mid-gut } & \multicolumn{3}{|c|}{ Digestive tract evacuated } \\
\hline & & Normal & $\begin{array}{l}\text { Plus } \\
\text { sodium } \\
\text { arsenite }\end{array}$ & $\begin{array}{l}\text { Plus } \\
\text { paris } \\
\text { green }\end{array}$ & Normal & $\begin{array}{l}\text { Plus } \\
\text { sodium } \\
\text { arsenite }\end{array}$ & $\begin{array}{l}\text { Plus } \\
\text { paris } \\
\text { green }\end{array}$ \\
\hline Euxsa segetum............. & 9.7 & $\begin{array}{l}\text { hours } \\
90-120\end{array}$ & $\begin{array}{c}\text { hours } \\
60 \pm\end{array}$ & $\begin{array}{c}\text { hours } \\
\ldots .\end{array}$ & $\begin{array}{c}\text { hours } \\
96-144\end{array}$ & $\begin{array}{c}\text { hours } \\
72 \pm\end{array}$ & $\begin{array}{c}\text { hours } \\
\ldots .\end{array}$ \\
\hline Pieris brassicae. . & 9.4 & $30 \pm$ & $12 \pm$ & 4-5 & $36 \pm$ & $12 \pm$ & $6 \pm$ \\
\hline Locusta migratoria... & 6.9 & $6-7$ & $10 \pm$ & $20 \pm$ & $9 \pm$ & $12 \pm$ & $24 \pm$ \\
\hline
\end{tabular}

* Data of Voskresenskaya (1936a)

tract, including the Malpighian tubules, and in the remainder of the body. The results expressed in percentage of the total arsenic ingested are summarized in table 3 .

TABLE 3

Distribution of Arsenic in Percentage of Total Arsenic Ingested*

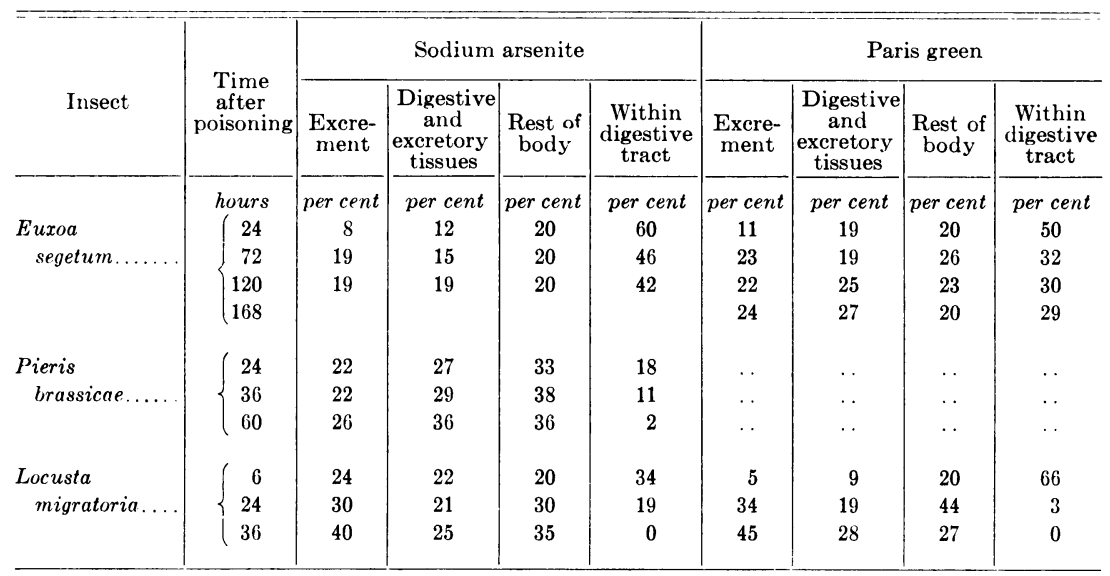

* Data of Voskresenskaya (1936a).

The smallest fraction of the ingested arsenic was absorbed from the food and passed into the general body tissues in the case of Euxoa segetum, but since the poisons were administered approximately in the ratios of the minimum lethal doses of sodium arsenite $(0.14 \mathrm{mg}$ of As per gram for E. segetum, $0.04 \mathrm{mg}$ As per gram for Pieris brassicae, and $0.03 \mathrm{mg}$ 
As per gram for Locusta migratoria), the data indicate that the firstnamed insect actually absorbed and excreted more arsenic than the others. That is, the amount which must be absorbed, as distinguished from that which must be swallowed to cause death, is greatest in $E$. segetum. In this insect, the amount of arsenic in the general body tissues from ingested sodium arsenite remained constant over a period of 5 days, which indicates that absorption and excretion proceeded at equal rates. The long persistence of poisoned food in the mid-gut enables absorption to continue for an extended period. On the other hand, in $L$. migratoria and possibly in $P$. brassicae, excretion at first lags behind absorption and the arsenic balance increases. Since the mid-gut of these insects is emptied within a few hours, absorption of arsenic from the food continues for only a short time, and thereafter the increase in the amount in the general body tissues is at the expense of that previously absorbed by the tissues of the digestive tract. With the more rapidly obsorbed paris green ( 44 per cent of the total amount in 24 hours), absorption first exceeded excretion and then fell behind it, so that the arsenic in the general body tissues passed through a maximum. To a lesser degree, this also occurred with paris green in E. segetum and sodium arsenite in $P$. brassicae. It is probably to be expected that when the amount of ingested arsenic is increased, more will pass through the digestive tissues and into the hemolymph. This was found to be the case with $P$. brassicae and L. migratoria; but a very peculiar situation occurs with E. segetum, for a nearly tenfold change in the amount of arsenic fed per gram of insect resulted in no appreciable change in the amount, approximately $4 \mu$ As per gram, which was found in the general body tissues. However, the amount in the digestive and excretory tissues increased. Voskresenskaya suggests that in $E$. segetum there is a blocking mechanism which restricts passage of arsenic out of the tissues of the digestive tract. The results can be explained equally well by a constant ratio between the rates of absorption and excretion.

Unfortunately, in this work no effort was made to measure the rate of accumulation of arsenic by the Malpighian tubules, and of course, determinations of arsenic in the combined digestive and excretory tissues tell nothing about how much is in either. Voskresenskaya points out that the lower $\mathrm{pH}$ in the mid-gut of Locusta migratoria is not correlated with readier absorption of arsenic, as would be predicted from the degrees of ionization at the given $\mathrm{pH}$ values. Whether this is due to other factors in absorption or to undetected variations of $\mathrm{pH}$ in small but highly absorptive regions of the mid-gut has not been determined.

The only other constituent of stomach poisons whose absorption by 
the insect gut has been studied appears to be lead. By the addition of a minute amount of radioactive thorium $B$ to lead acetate, Campbell and Lukens (1931) were able to prepare a lead arsenate which could be quantitatively traced during its passage through the body of fifth-instar silkworms. Food is passed through the digestive tract of this insect with great rapidity, for the first traces of lead appeared in the feces within less than an hour after the toxic meal was taken. Elimination of lead is very fast, for about half was lost within 2 hours after a moderately toxic dose was ingested, and within 24 hours, nearly all the lead from either acid or basic lead arsenate was eliminated. Larger doses incapacitated the larvae more quickly and fewer pellets and less lead were voided. In this work, no analysis of the digestive-tract tissues was made and hence no conclusions can be drawn regarding absorption of lead into either the digestive tissues, general body tissues, or excretory system. The method is admirably adapted to such a study, however. The authors point out that deductions as to the elimination of arsenic by the silkworm should not be made from this work since lead and arsenic probably do not follow the same course.

In the previous discussion, mention has been made of several factors which influence or limit the absorption of toxic substances from the digestive tract of insects. While the actual injurious effects are concerned with changes in the structure or functions of the cells and tissues, probably the most obvious indication of irritation by poisons is the reluctance or refusal of insects to eat their normal diet after stomach poisons such as arsenicals have been added to it. This may be of great practical importance; for by avoiding the more heavily treated regions of plants, a pest may more or less completely escape destruction. In a detailed study with larvae of Euxoa segetum, Euproctis chrysorrhoea, and Pieris brassicae and nymphs of Locusta migratoria, Dodonov (1936) found the first two cannot be controlled successfully with sodium arsenite because they refuse to eat treated food in sufficient amounts. Increase in the amount of arsenic applied is useless, for then less food is eaten than with light application. He concluded that it is preferable to use sodium fluosilicate for control of these insects since they eat it readily. On the other hand, $P$. brassicae and $L$. migratoria accept lethal doses of arsenic with but little hesitation.

Another obvious evidence of the irritating effect of certain stomach insecticides is the diarrhea which often follows the consumption of poisoned food. This condition is particularly marked with the more soluble arsenicals. All insects are not affected in the same way, however; for as mentioned earlier Voskresenskaya (1936a) found that food containing 
sodium arsenite or paris green passes through the digestive tract of Locusta migratoria more slowly than normal food.

This same worker (Voskresenskaya, 1936b) observed a very interesting kind of reaction to irritation in the cutworm, Euxoa segetum. Within about an hour after consuming food poisoned with an arsenical, the insect vomits a large part of the toxic meal. This action together with the very slow rate at which arsenic is absorbed from the mid-gut (Voskresenskaya, 1936a) account for this insect's high resistance to arsenic. In order to study the behavior of the gut itself, larvae of E. segetum and of Pieris brassicae were opened dorsally in such a manner as to expose the digestive tract without injuring the nervous centers. If the gut is kept moist with a little Ringer's solution, the behavior is apparently normal and peristaltic motion continues at a uniform rate. A characteristic difference between the two insects is that there is a well-marked contraction three times a minute of the anterior sphincter between the fore- and midgut in E. segetum but no corresponding action in the other insect.

The addition of $0.1 \mathrm{ec}$ of sodium arsenite solution ( $0.05 \mathrm{mg}$ As per cc) results within a few minutes in cessation of the contractions of the anterior sphincter of Euxoa segetum. Shortly thereafter, very violent and frequent contractions (10 times per minute) of the anterior sphincter of this insect begin and the contents of the fore-gut and of part of the midgut are ejected. No effect of arsenic upon the anterior sphincter is to be observed in the case of Pieris brassicae. As a result of tests with these and other insects, Voskresenskaya concludes that a diminution followed by a great increase in contractions of the anterior sphincter is characteristic of all insects which are caused to vomit by arsenicals and consequently are difficult to kill with these insecticides. Among such insects may be mentioned the silkworm, which Cook and McIndoo (1924) found to void 90 per cent of the lead arsenate which it ingested.

Voskresenskaya (1936b) has offered an explanation of the effects of arsenic on Euxoa segetum larvae in terms of reactions of the nervous systems controlling intestinal movements. By analogy with animals, stimulation of the sympathetic nervous system is assumed by her to result in relaxation of the muscles of the gut, particularly of the anterior sphincter. This first effect of arsenic, is soon followed by a depressing effect upon the sympathetic nervous system, possibly accompanied by irritation of the parasympathetic system, which causes the violent contractions of the sphincter that result in vomiting. Of course direct addition of soluble arsenic to the body cavity speeds up the sequence of events greatly as compared to the effects when arsenic is taken by mouth, for example, 5 minutes instead of an hour or more. The interpretation of- 
fered by Voskresenskaya is very interesting but should not be taken as more than a suggestion. Proof or disproof of the theory must await a study of action potentials of the insect antonomic nervous system under the influence of toxic substances. One practical result of the work is the proposal that the reactions of the anterior sphincter be studied as an index of sensitivity to arsenic. The observation mentioned by O'Kane (1923) that addition of bismuth subcarbonate to lead arsenate improved the control of the Japanese beetle, apparently exemplifies the suggestion of Voskresenskaya that incorporation of substances which lessen the possibility of depression of the sympathetic nervous system would render arsenicals more effective, for bismuth salts are commonly used in medicine to reduce vomiting and intestinal cramps.

The secretion of the so-called digestive juices containing enzymes, salts, and probably other chemical reagents required for the preliminary breakdown of foodstuffs is an extremely important function of the digestive tract, and any effects of ingested poisons thereon are worthy of study. An investigation of the fluctuations in $\mathrm{pH}$ following the ingestion of sodium arsenite by the larvae of Euxoa segetum and Pieris brassicae and the nymphs of Locusta migratoria has been reported by Skrjabina $(1936 b)$. It was pointed out earlier that normal $\mathrm{pH}$ in the mid-gut of the first two insects is strongly alkaline, 9.5 and 9.7 respectively, after several hours' fasting. In $L$. migratoria, however, the corresponding $\mathrm{pH}$ is practically neutral. The food used in Skrjabina's experiments consisted of leaves which when crushed gave a $\mathrm{pH}$ value of approximately 6.4. Hence the initial drop in $\mathrm{pH}$ within the mid-gut immediately after feeding begins may be attributed to the food. Within about $1 / 2$ hour, a steady rise in $\mathrm{pH}$ begins, which in 3 to 6 hours reaches a value as much as 0.5 $\mathrm{pH}$ unit above the fasting condition. After an interval which depends upon the persistence of food in the mid-gut (see earlier discussion of Voskresenskaya's results, $1936 a$ ), the $\mathrm{pH}$ returns again to the original level. Hence there is normally a cyclical variation in $\mathrm{pH}$ within the midgut of the three insects, which is not great enough to affect seriously the solubility or the ionic state of stomach poisons. Under the influence of approximately minimum lethal doses of sodium arsenite or paris green, however, conditions are entirely different. The initial drop in $\mathrm{pH}$ is soon succeeded by a rise greater than that normally occurring at the given time, but instead of persisting, this high $\mathrm{pH}$ gives way to a prolonged decrease, so that the $\mathrm{pH}$ may drop as low as 8.0 in the case of $\boldsymbol{E}$. segetum and $P$. brassicae and 6.0 in L. migratoria. These changes in $\mathrm{pH}$ are sufficiently great to alter the solubility of the slightly soluble arsenicals (see H. S. Swingle, 1938; Lavrov and Paramonova, 1936) and probably 
have an appreciable effect upon the toxicity. The early marked rise in $\mathrm{pH}$ is attributed to an initial stimulating effect of arsenic upon the production of digestive fluids so that the lowering due to ingestion of food is more than overcome. The subsequent fall is due in part to cessation of flow of digestive juice (that is, the secondary depressing effect of arsenic). This, however, does not account for the very low $\mathrm{pH}$ values reached, which probably are to be attributed to secretions liberated during the inflammatory and corrosive processes to be described later. The effects upon $\mathrm{pH}$ are proportional to the amount of arsenic consumed, and less than $0.03 \mathrm{mg}$ As per gram has no appreciable effect upon $E$. segetum (minimum lethal dose $0.14 \mathrm{mg}$ As per gram).

Sodium fluosilicate has but little effect upon the $\mathrm{pH}$ of the mid-gut in the insects studied by Skrjabina. The preparation which he used was strongly acidic and the large amount given to Euxoa segetum $(0.317 \mathrm{mg}$ per gram) reduced the $\mathrm{pH}$ in the mid-gut by about $1 \mathrm{pH}$ unit so that the normal cycle of $\mathrm{pH}$ variation was followed at a level lower by this amount. With the other insects, which received smaller doses, no effect upon $\mathrm{pH}$ was found. Unfortunately, there do not seem to be data on the $\mathrm{pH}$ effects for other insects or other stomach insecticides. Studies on insects whose mid-gut consists of portions differing in $\mathrm{pH}$, for example, the larva of the blowfly, Lucilia sericata, would be of particular interest in this connection.

In the majority of insects so far investigated, the digestive enzymes are strongly similar to, if not identical with, the corresponding ones of vertebrates. Certain minor differences in $\mathrm{pH}$ optima have been noted, as with the proteinases of fleshfly larvae (Hobson, 1931) and of tsetse flies (Wigglesworth, 1929). Insects having unusual diets usually possess special enzymes adapted to the decomposition of these foodstuffs, as in the case of the wood-eating beetles (Ripper, 1930; Mansour and MansourBek, 1937), or clothes-moth larvae and wax-moth larvae (P. Krüger, 1933; Duspiva, 1936; Linderstrøm-Lang and Duspiva, 1936).

The effects of various chemicals upon the activity of insect digestive enzymes have been studied very slightly, and the results are trivial in comparison to those which are available for enzymes from the digestive tract of animals (for good summaries of the latter see Haldane, 1930, chapter VII ; H. Tauber, 1935). As a part of his investigation on the mechanism of action of arsenic, Fink (1932) fed foliage sprayed with paris green or lead arsenate to Colorado potato beetles, Leptinotarsa decemlineata. When feeding had ceased, the insects were dissected, the digestive tracts washed free from food, and the mid-guts separated. These were ground in sand and the pulp extracted with water or 50 per 
cent glycerol. After adjusting to several $\mathrm{pH}$ values, the enzyme activity of the extracts was compared with that of similar extracts from normal beetles. The results showed no effect of arsenic upon amylase, lactase, maltase, invertase, lipase, or the proteolytic enzymes. But direct oral injection of much larger amounts of the arsenicals inhibited action of the proteolytic enzymes. The difference in these results may be attributed to the excessive amounts given by injection.

In a study of the enzymes occurring in the crop of the grasshoppers, Stenobothrus sp. and Tettigonia cantans, Schlottke (1937a) found the action of the proteinase to be completely inhibited by hydrogen cyanide and to be strongly depressed by hydrogen sulfide. The lipase from the mid-gut was reduced in activity about one-half by 0.06 per cent sodium fluoride. In a later study, Schlottke (1937b) found lipase from the caeca of the mid-gut of the cockroach, Periplaneta orientalis, to be inhibited about one-half by 0.06 per cent sodium fluoride and about one-fifth by half that concentration. There seems to be no indication from the available data that the serious toxic effects of stomach insecticides result from their actions upon the digestive enzymes.

On the other hand, exposure to the digestive juices may alter the toxicity of an insecticide. Woke (1939) fed turnip-leaf sandwiches containing either pyrethrum powder or the pyrethrins from a kerosene extract to sixth-instar southern armyworms, Prodenia eridania, and found neither the feces nor any part of the body to be toxic to larvae of the mosquito Culex fatigans after a few hours. The detoxifying effect is not conditioned upon passage through the digestive tract, for when pyrethrum is mixed with any of several ground tissues, the toxicity is rapidly destroyed, the effect decreasing in the order: fat body, skin and muscles, digestive tract, blood. Similar experiments with sandwiches containing rotenone (Woke, 1938d) showed that this compound passes through the armyworm's digestive tract without change and is not affected by exposure to finely ground tissues of the body.

In an investigation probably concerned with the oxidative enzymes in insect gut tissue, Tareev and Nenjukov (1931) removed the digestive tract of the grasshopper, Calliptamus sp. and soaked the separated fore-, mid-, and hind-gut portions in solutions of sodium arsenite (0.031 to 1.0 per cent) for 24 hours. These were then washed thoroughly and placed in $1: 20,000$ solutions of methylene blue. Any part of the gut kept in 0.6 per cent salt solution instead of the arsenite completely decolorized the methylene blue solution within 24 hours. The decolorizing power of the fore-gut was affected but little by soaking in arsenite solution, that of the hind-gut was decreased appreciably by the higher concentrations of 
the arsenite and in the case of the mid-gut 0.5 per cent arsenite almost completely prevented the reaction with methylene blue. Tareev and Nenjukov conclude that the necrotic effects from exposure to arsenic are manifested primarily in the mid-gut. These effects are not diminished seriously in the presence of food, for the addition of 1 per cent sodium arsenite to the diet of the grasshoppers caused the gut to respond in the same manner as when it was kept in the stronger solutions, that is, no decolorizing of the methylene blue occurred.

Histological methods offer one of the best approaches to a study of the ultimate cellular changes caused by insecticides. Pilat $(1935,1936)$ examined the mid-gut of larvae of the tortoise-shell butterfly, Vanessa urticae, of the gypsy moth, Porthetria dispar, of the cabbage butterfly, Pieris brassicae, and of nymphs of the migratory locust, Locusta migratoria, at intervals after they had fed on leaves poisoned with sodium arsenite, paris green, or sodium fluosilicate. His reports are illustrated by detailed drawings made from stained sections. The normal mid-gut of a $V$. urticae larva consists of columnar epithelial cells with a striated hem on the free surface. The other end of these cells rests upon a thin connective membrane beyond which is a layer of circular muscles and one of longitudinal muscles. The first sign of arsenical poisoning is an increased secretion by the columnar cells (compare Skrjabina, 1936a) with agglomeration of some unknown brown material within the cells. Then small pieces are lost from the inner end of the cells and the latter begin to loosen in large sheets from the connective membrane. As the severity increases, the striated hem disappears and the cellular membranes become indistinct. Finally the epithelium is lost entirely and the connective membrane left bare. The columnar cells are not killed immediately upon detachment from the connective membrane, for mitotic figures may be observed in those floating freely in the debris. The severity of the tissue destruction is proportional to the dose of arsenic and, in general, to the time since ingestion. All effects are more pronounced in the anterior portion of the mid-gut.

Similar results were obtained with the locust. By giving measured amounts of arsenic, Pilat determined that the extreme destruction may be brought about within 7 hours after a dose of $0.08 \mathrm{mg}$ per gram is given, although usually the changes come about more slowly.

A closely similar sequence of events occurs when sodium fluosilicate is given to either Vanessa urticae or Locusta migratoria. The amounts needed, however, are much larger, for example, Pilat found that 0.37 $\mathrm{mg}$ per gram led to the stage of disappearance of the striated hem and fusion of the epithelial cells in 22 hours in the case of the locust. 
The other two insects, Porthetria dispar and Pieris brassicae, showed very little change in the digestive tract after ingestion of either arsenic or fluosilicate, and no definite toxic effects could be attributed to these substances although amounts were given (up to $0.1552 \mathrm{mg}$ of arsenic per gram and $0.729 \mathrm{mg}$ of fluorine per gram) which presumably led to death of the insects.

In this laboratory, Wilson ${ }^{6}$ has made a detailed histological study of the mid-gut of Pieris rapae larvae after the ingestion of known amounts of sodium arsenite. The minimum lethal dose is approximately 0.025 $\mathrm{mg}$ of arsenic per gram. Time of death varied greatly-from 1 day to nearly 2 weeks. By means of special staining technique (Craig and Wilson, 1937), it was found possible to follow the secretory and resting cycle of the mid-gut cells and to show that hypersecretion is induced within 2 hours after ingestion of arsenic. The sequence of effects thereafter agrees entirely with the description given by Pilat (1935, 1936), for Vanessa urticae. In addition, Wilson found that arsenic causes disintegration of the peritrophic membrane. Injection of soluble arsenic into the body fluid in the same amounts as by mouth caused the same changes in the mid-gut, but no marked cellular effects were observed in other parts of the body. There is evidently a special affinity of arsenic for mid-gut epithelial cells. Whether the poison reached them from the body cavity by passing through the muscular layers and the connectivetissue membrane or whether it was excreted by the Malpighian tubules and moved backward into the mid-gut was not determined. The results of Pilat and of Wilson clearly show that the destruction of tissue and derangement of function in the mid-gut of insects which have ingested arsenic are sufficient to account for the subsequent mortality. An unexplained problem remaining from their work is the marked difference in the effects upon the mid-gut for the closely related insects, $P$. brassicae and $P$. rapae.

In a very recent investigation with the southern armyworm, Prodenia eridania, Woke ${ }^{7}$ found the characteristic disintegration of the mid-gut cells following ingestion of arsenicals. Sodium fluoride caused large vacuoles to appear and barium fluosilicate contracted the mid-gut and threw its walls into folds. No changes recognizable with certainty were

${ }^{6}$ Wilson, C. A study of the toxicity of arsenic to cabbage butterfly larvae (Pieris rapae Linn.) and its mode of action. Thesis for the degree of Master of Science, University of California, 1936. (Typewritten.) Copy on file in the University of California Library, Berkeley.

${ }^{7}$ Woke, P. A. Effects of some ingested insecticides on the intestinal wall of the southern armyworn, Prodenia eridania (Cram.). Paper read at the 51st Meeting of the American Association of Economic Entomologists, December 26-30, 1938. Unpublished. 
caused by rotenone, phenothiazine, or sodium fluoaluminate. This work indicates that the various fluorine compounds exert specific effects upon the mid-gut.

\section{THE CIRCULATORY SYSTEM}

In attempting to appraise the effects of toxic substances upon the circulatory system of insects, certain points concerning its structure and functions may well be kept in mind. In the first place, the elaborate system of arteries, capillaries, and veins characteristic of vertebrates is largely lacking, and the body fluid encounters but little resistance in moving about. There is no necessity for a powerful heart equipped with efficient valves, and in fact, reversal of heartbeat is not uncommon (Gerould, 1933). Inhibition of heartbeat is not necessarily fatal within a limited time, for Campbell (1926) reported that the silkworm lives for several days after its heart is stopped by injection of eosin solution. Such a condition of sluggish and irregular circulation is only possible because the blood of insects is not an essential factor in supplying oxygen to the tissues. The lack of an oxygen-carrying compound, for example, hemoglobin, in the blood is an added indication that respiration is not dependent upon the circulatory system. In fact, the oxygen capacity of the blood of the southern armyworm, Prodenia eridania, is less than that of normal saline solution (Babers, 1938).

The most obvious method for studying blood circulation in insects is by observation of the rate and intensity of contraction of the heart. As is the case with nearly all physiological processes, conditions are altered by temperature, kind of insect, and even stage of development. Unfortunately, any detailed explanation of interference with heart action in insects is difficult because of uncertainty as to whether it is under myogenic or neurogenic control (Maloeuf, 1935), that is, whether contraction of heart muscle is initiated within the heart itself or by stimulation from ganglionic cells of the nervous system. Up to the present, however, studies with toxic substances have been of such a general nature that the hypothesis adopted makes little difference. The normal rates of heartbeat of thirteen insect species, as determined by various workers and summarized by Kozhantchikov (1932), vary from 12-20 per minute at $18^{\circ} \mathrm{C}$ for the larva of Lucanus cervus to 139-140 per minute for adult Sphinx ligusti. In his own work, Kozhantchikov found the action of the heart of Blatta orientalis to be affected by the concentration of salts and the $\mathrm{pH}$ of the liquid in which it was immersed. Normal behavior occurred in a modified Ringer's solution of concentration equal to 1 per cent salt and $\mathrm{pH}$ near neutrality. Reduction in concentration decreased the rate 
and lengthened the resting phase until at 0.6 per cent the heart stopped in that phase. Hypertonic solutions increased the rate until the heart stopped in the systolic (contraction) phase at 1.4 per cent. Alkali at 0.005 per cent concentration decreased the rate and at 0.1 per cent killed the heart at once. Sensitivity to acid is greater, for death occurred at 0.03 per cent acetic acid.

$\Lambda$ number of common fumigants stop the heartbeat of the tulip aphid, Macrosiphum tulipae (Kirschner, 1932). Since concentration was not controlled, the exposures required are not accurate indexes of relative toxic action upon the heart, but it is probably significant that the fumes of burning tobacco (nicotine) stopped heart action in 2-3 minutes, carbon disulfide in 4-7 minutes, ethyl acetate in 5 minutes, carbon tetrachloride in 13 minutes, and a mixture of the last two in 11 minutes. Formaldehyde and nitrobenzene acted very slowly, requiring nearly an hour before heartbeat stopped entirely. With carbon tetrachloride, ethyl acetate, or benzene, an initial increase in rate of beat preceded the depressant effect.

Heart action in the silkworm is affected in a characteristic manner by arsenic (Campbell, 1926). Injection of $0.02 \mathrm{mg}$ of arsenic per gram of body weight as sodium arsenite caused an immediate increase in rate of beat, followed by a rapid decrease, so that within 5 minutes the rate was half that of normal. Sodium arsenate caused the same sequence of action but much more slowly : the rate declined by half in somewhat over an hour. Ingestion of $0.05 \mathrm{mg}$ of arsenic per gram by mouth resulted in no initial stimulus of heart action and the decrease occurred much more slowly. There is an interesting relation between this work and that of Wilson (see p. 355), for serious decrease in heart action occurred within 2 hours, which is the time in which the hypersecretion of digestive juice by the cabbage butterfly larvae was first noticed. If the two insects can be compared in this way, it is indicated that the effects of ingested arsenite are shown upon the heart action before there is any visible damage to the mid-gut.

Dilute solutions of several organic thiocyanates decrease the rate of beat of the isolated heart of Blatta orientalis (Yeager, Hager, and Straley, 1935), until ultimately it stops in diastole. At the same time, there is a general dilation of the whole heart tube which seems to be due to increased pull of the alary muscles rather than to loss of tonus of the heart muscles. This interpretation is in agreement with the fact that thiocyanates increase the tonus of vertebrate muscle. Among the ten compounds tested, the methyl and ethyl thiocyanates were least effective, the propyl and butyl next, while the most active group included 
more complicated molecules whose action probably is due only in part to the thiocyanate radical. In similar experiments with pyrethrum extract, these same workers found that the cockroach heart stopped in systole.

Pyrethrin apparently does not affect the heart action of all insects in the same way. With larval heart preparations of the wax moth, Galleria mellonella, Belleuvre (1938) found the beat to be slowed by prolongation of the diastole phase, until eventually the whole dorsal vessel passed into diastole except for feeble contractions at long intervals. The anterior portion ceased beating first. A plot of time for total arrest of heartbeat versus concentration of pyrethrins gave a rectangular hyperbola, that is, the concentration divided by the interval after exposure is a constant. In experiments in which Corethra plumicornis larvae were kept in aqueous suspensions of pyrethrum powder, F. Krüger (1931) was impressed by the continuous convulsions to which the organisms were subjected and he examined the heart action to determine if it too went into spasms. One hour after general convulsions started, the heart action was apparently normal and by the following day it had decreased only a third. Krüger attributed the effect on the heart to general weakening resulting from the long-continued convulsive reaction of the body muscles.

The application of derris dust to silkworms, mosquito larvae, diamond back cabbage worms, American cockroaches, or tomato cutworms resulted in slowing of the heartbeat while body movements were still normal (Tischler, 1935). Heart action, though slow and feeble, continued until death of the insects.

A comparative study of the effects of nicotine solutions upon the isolated hearts of the American cockroach, Periplaneta americana, and of later instar southern armyworms, Prodenia eridania, showed the former to be much more sensitive when exposure was made by immersing the organs in the various solutions (Yeager and Gahan, 1937). With the cockroach, low concentrations of nicotine, such as 0.0125 per cent, stimulated the contraction rate without a subsequent depression; higher concentrations, such as 0.4 per cent, caused strong stimulation at first and a partial depression after a half hour or so; still higher concentrations, such as 2.75 per cent, caused violent stimulation for a few minutes followed by total cessation of heartbeat; the amplitude is greatly decreased and the heart finally stops in systole. Hence the alary muscles cannot be strongly contracted, and the situation is like that with pyrethrum as mentioned previously. If the exposure was short enough, all these stages were reversible. The southern armyworm shows only very transient increase in rate of heartbeat and decrease occurs at higher nicotine con- 
centrations (5.5 per cent) than in the case of the cockroach. The amplitude is not affected and the heart stops in partial or complete diastole. With isolated heart preparations of the grasshopper, Melanoplus differentialis, nicotine causes an increase in amplitude of beat, but continued exposure to 1 per cent nicotine leads to complete paralysis (H. L. Hamilton, 1939). This effect is reversible, for normal function is restored by bathing the heart in warm physiological salt solution. The relatively great resistance of heart action to nicotine is illustrated by certain experiments of Yeager and Gahan (1937) in which intact armyworms were injected. Over a range of concentration, heart action persisted but other muscles were completely paralyzed. Similarly, Klinger (1936) found heart action to continue in larvae of Vanessa io or Dendrolinus pini larvae for 6 days after dusting with rotenone powder, when the insects were entirely helpless and their bodies were partially atrophied.

The dorsal vessel of the larva of the sawfly, Pteronus ribesii, is extremely sensitive to the hydrogenated dipyridyl compound anabasine (Tarasova, 1936), which is an isomer of nicotine. Immersion of the organ in a 0.00001 per cent solution of anabasine sulfate causes immediate and final cessation of all pulsation. On the other hand, application of a 1 per cent solution to the intact larva leads to a fourfold increase in rate of heart action which persists for several hours. Evidently the slow penetration of the compound enables its initial stimulating effect to become evident, whereas upon direct contact only the paralyzing effect is noticed. In similar experiments with the oriental cockroach, Blatta orientalis, Tarasova found the dorsal vessel of this insect to be only temporarily affected by anabasine.

By means of an ingenious mechanograph, which acts on the principle of the pantograph, Yeager $(1938,1939)$ has been able to amplify motions of the heart wall of the cockroach some 400 to 600 times so that the true nature of the cardiac cycle can be studied in detail. When the heart is functioning normally, there are three phases: systole (contraction), diastole (relaxation), and diastasis (rest). Nicotine inhibits the diastole phase so that the amplitude decreases and eventually systolic arrest is reached. The whole process of toxic effect and recovery can be studied for any section of the heart either intact or in separate parts. It is obvious that this method will be of value with all manner of substances whose cardiac effects are of interest.

Since the blood of insects directly bathes all vital organs, its chemical and physical properties and cytological makeup might logically be expected to be sensitive to the presence of toxic substances taken into the body. In order to test the truth of this assumption, rather complete infor- 
mation regarding the normal state is necessary, but, unfortunately, is not available. The blood of most species is slightly acid (for summaries see Wigglesworth, 1939, Hoskins and Craig, 1935). The $\mathrm{pH}$ may vary with sex and state of development, as in the silkworm (Demjanowski, Galzowa, and Roshdestwenska, 1932) and in Tenebrio molitor (Kocian and Spacek, 1934). For this reason, great caution is necessary in attempting to relate toxic action to $\mathrm{pH}$ changes. The total concentration of solutes is markedly different in various species and in certain ones is subject to astonishing seasonal changes: Vinogradskaya (1935) found that the blood of overwintering Anopheles maculipennis females freezes at $-2.275^{\circ} \mathrm{C}$, whereas that of well-fed fall females froze at $-0.787^{\circ}$. The relation of this property to cold hardiness is obvious. Adjustment is very rapid, for example, there was a change of $0.3^{\circ}$ within 20 minutes after the winter females were brought out of their cold hibernating place. With many insects, as the blood-sucking bug Rhodnius (Buxton, 1932), the solute concentration in the hemolymph is affected by the humidity or saturation deficiency of their surroundings. Such results show plainly that care must be used in estimating the effects of poisons upon the solute concentration in the blood.

O'Kane and Glover (1935) noted that very little blood was present in cockroaches which had been exposed to arsenic. A similar observation was made by Shull, Riley, and Richardson (1932) regarding cockroaches killed by exposure to carbon disulfide or pyridine. This condition is likely to arise with any substance which causes hypersecretion by the mid-gut cells and consequent loss of much water in the feces, and also whenever excessive ventilation of the respiratory system occurs.

In accordance with the hypothesis discussed earlier (p. 315) that $\mathrm{pH}$ affects the penetration of some toxic substances into membranes and cells, it is to be expected that the $\mathrm{pH}$ of insect blood will be related to relative intensity of effect upon those tissues, such as the nervous, reproductive, and excretory systems, which are most readily reached through the blood. This subject was briefly discussed by Yeager and Gahan (1937) in relation to the effect of nicotine and its salts upon the isolated heart of the cockroach, but they apparently did not have sufficient data to draw any conclusions. Gösswald (1934) studied the relative susceptibility of the larvae of several forest insects-such as Lymantria monacha, L. dispar, Euprostis chrysorrhoea, and Dendrolinus pini-to pyrethrum dust and found a correlation between high $\mathrm{pH}$ of the blood and resistance to the poison. The conditions predisposing to higher $\mathrm{pH}$ are increase in age and degree of development, exposure to humid air or rain, hairy covering, and sex-female larvae are more alkaline and more 
resistant. General agreement with this conclusion regarding $\mathrm{pH}$ of the blood and resistance to pyrethrum was reached by Klinger (1936) from experiments with eleven species of Lepidoptera.

In spite of the labors of many investigators, there is still little agreement on the kinds of cells in insect blood and their functions. The great majority are included within two classes which may be called leucocytes and enocytoids. The former appear first as very small cells which often are in some stage of mitosis. Later they elongate and have the power of ingesting any kind of foreign material in the blood stream; they thus act as phagocytes and are particularly numerous and active during molting or metamorphosis, when there is much debris from dead cells in the blood stream. Another property is the ability to spread out into a thin sheet comparable to endothelial structures. The enocytoids are usually round or oval in shape. They are not phagocytic nor do they form membranes. While they are more numerous at times of transformation, their functions are not clear. In addition to those two forms, there are numerous fat globules, partially disintegrated muscle cells, and other poorly defined particles.

An obvious point of interest in connection with the effects of toxic substances is whether a change in the number of cells per unit volume occurs. The matter is greatly complicated, however, by the tendency of cells in the normal insect to collect along the walls of the heart or at other places in the body. Thus Yeager and Tauber (1932) found the number of cells per cubic millimeter of blood from Periplaneta fuliginosa to vary from 15,000 to 60,000 and Fisher (1935) with P. orientalis found 4,200 to 45,800 . Fisher attributed part of the variation to difficulties in counting caused by the rapid coagulation of insect blood. Of course, there is no proof that such variation is due to temporary removal of cells from the circulation, but the lack of uniformity in apparently normal insects necessitates the use of many individuals in studies with poisons in order to obtain averages that are statistically significant. The attempts to secure a uniform reference condition by exposing individuals to acetic acid fumes (Shull and Rice, 1933) have not improved the situation much; Fisher (1935) found a variation from 8,300 to 83,600 cells per cubic millimeter in the blood of $P$. orientalis treated in this way. Thus exposure to acetic acid approximately doubled the cell count in this insect but did not diminish the variation between individuals.

Thirty-four gaseous compounds were studied by Shull, Riley, and Richardson (1932) to determine their effects upon the blood of the cockroach, Periplaneta orientalis. Most of them had no visible effect, but the cockcoaches killed by carbon disulfide contained only a small volume of 
blood in which the cells were few in number and usually granular in appearance. Pyridine also caused a reduction in blood volume but the cell count per unit volume was normal. Ammonia caused especially rapid coagulation, and crystals resembling magnesium ammonium phosphate were formed. Fisher's (1936) results indicated that carbon disulfide has no definite effect upon the number of cells in cockroach blood, but hydrogen cyanide, ether, or pyridine caused a greater cell count than when acetic acid was used.

The effects of stomach poisons upon the blood can only be exerted after absorption from the mid-gut has occurred. Thus Tareev and Nenjukov (1931) fed wheat stems sprinkled with sodium arsenite solution to grasshoppers (Calliptamus sp.) and found no changes in the blood 2-3 hours afterward. Several hours later when the insects were very sick, many of the blood cells were abnormal : some were abnormally large; the nuclei had lost their normal round shape and become irregular, sometimes divided into small clumps with grains scattered through the cytoplasm; the latter was very irregular in shape, more or less vacuolated, and sometimes shrunk. The authors classify insect blood cells in a slightly different manner from that given above but the changes they describe evidently occurred chiefly among what are here termed "leucocytes." Sodium fluoride, also fed on wheat stems to insects, caused no apparent change in the grasshopper blood at any time up to death of the insects. As was mentioned previously, O'Kane and Glover (1935) obtained abnormally small volumes of blood from cockroaches poisoned with arsenic. Fisher (1936) noted that fewer cells were present per unit volume. Hence the effects must be exerted on both cells and plasma, and the changes in number of cells cannot be accounted for by the change in the water balance between blood and tissues.

It is probably to be expected that the serious effects of arsenic upon blood cells would be accompanied by changes in the chemical constitution of the blood. The nomprotein nitrogen of cockroach blood from normal individuals on various diets and from arsenic-poisoned individuals was studied by Nenjukov and Tareev (1931). Their results may be summarized as follows :

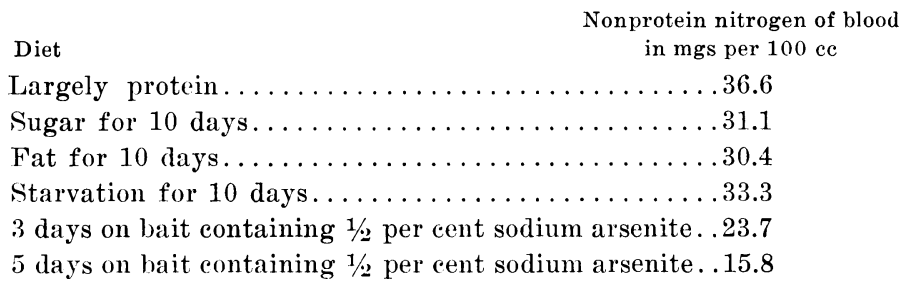


Diet apparently has a small effect, but arsenic causes a drastic decrease in the nonprotein nitrogen, which doubtless includes that from a very large number of compounds, such as ammonia, urea, uric acid, amino acids, creatin, etc. Since practically nothing is known of the details of nitrogen metabolism in insects, it is not possible even to guess as to the meaning of the observed changes in blood composition.

Ingestion of sodium arsenite by fifth-instar or adult Locusta migratoria results in changes in the blood only when there are severe and obvious signs of poisoning (Pilat, 1935, 1936). When this occurs, along with destructive changes of the cells, there appear many new cells which apparently are the first stage of the leucocytes, for they are very small and often are observed in mitosis. Precisely the same situation was observed in the blood of certain locusts which died of some bacterial disease. Pilat is of the opinion that any toxic condition hastens the formation and division of cells in the blood, just as was observed in the case of the mid-gut columnar cells (p. 354).

\section{THE EXCRETORY SYSTEM}

In the broadest sense, the excretory system includes all portions of the body which have to do with elimination of the end products of metabolism and useless or harmful ingredients of the diet. The ultimate purpose of this elaborate arrangement is to maintain the circulating fluid, and hence all other tissues of the body, in a more or less constant condition which differs in important particulars from one portion to another but is in each case adapted to the needs and functions of the cells and tissues involved. In vertebrates the concentrations of a whole host of substances are strictly regulated, such as hydrogen ion, sodium, calcium, and other metallic ions, chloride, phosphate, and other nonmetallic ions, carbohydrate, oxygen, and carbon dioxide. In general, the variations permissible without harm in insects are not known and they probably differ in the various species. Evidence that certain conditions, at least, are not strictly circumscribed in insects has been discussed in previous sections. Hence, it is unlikely that failure in functions of an excretory organ, such as the Malpighian tubules, due to injury from an insecticide, will lead to rapid death. It is possible, however, that such failure may alter the appetite, the activity, or the fecundity of the affected individuals and thus be of practical importance regardless of their ultimate death or recovery.

Toxic effects upon the excretory system may be studied by gross or cytological examination of the Malpighian tubules and possibly of other tissues such as the fat body, by determination of variations in the con- 
traction rate of the tubules (Yeager and Hager, 1934) and by chemical analysis of the urine and of the blood. The difficulties in such work are obvious: excretion is an example of semipermeability of cell membranes which may be disturbed in function without visible change of structure; micromethods of chemical analysis are sensitive enough for only a few substances; in most insects the urine is voided with the feces and uncontaminated samples cannot be obtained. Nevertheless, in the case of one insect, the blood-sucking bug, Rhodnius prolixus, genuine progress has been made toward acquiring quantitative data on the normal excretory process (Wigglesworth, 1931). After a meal this insect passes urine rapidly for several hours and thereafter at longer intervals, but often no feces are passed for a week or longer. Wigglesworth has made a detailed study of the normal urine and of the intimate structure of the Malpighian tubules, but as yet no information has been published on the effects of toxic substances. In Rhodnius the distal two-thirds of each tubule absorbs inorganic salts, potassium urate, etc., from the body fluid. In the proximal portion, water and the potassium, probably as the bicarbonate, are returned to the blood and free uric acid is left within the tubules. In this and in other insects, the rectal gland probably also assists in reabsorbing water (Wigglesworth, 1932), for conservation of water is a primary problem of most land insects, and change of the urine from its original dilute solution form to a semiliquid pellet or a dry powder has been found to occur in the lower part of the Malpighian tubules or the rectum in numerous insects.

A study of the functions of the Malpighian tubules of Tenebrio molitor larvae has been made by Patton and Craig (1939), who opened the larvae in such a manner that the tubules could be placed in any desired solution held in a nearby cup without disturbing the connections of the tubules with the intestine nor the functions of the latter. They found that the conductivity of solutions of approximately 2 per cent sodium chloride did not change when the tubules were kept therein but that the volume decreased, that is, there was nonselective absorption of the whole solution. If the rectum, properly ligated to prevent discharge of its contents, was placed in another cup of water, the salt absorbed by the Malpighian tubules passed into the gut and in part reached the water surrounding the rectum. Similar results were obtained with glycine, glutamic acid, uric acid, and urea, but the rate of passage differed for each substance. This technique offers a method for detailed study of the functions of both Malpighian tubules and of the rectum and of derangements in function caused by toxic substances, but no data are at hand as yet.

Aquatic insects often live in water whose salt concentration differs 
from that of their body fluid and accordingly there is need for accumulation of salts from the water, in case it is fresh, or elimination of excess salts if the surrounding solution is hypertonic. In the case of Chironomus, Culex, and Aedes larvae, these functions are performed in part at least by the anal papillae (Pagast, 1936; Koch, 1938; Wigglesworth, $1933 a, 1938 a)$. Hence these organs may be considered as part of the excretory system. In strong salt solution, such as 5 per cent sodium chloride, the anal papillae turn gray, their lumens swell, and the nuclei of the cells disintegrate (Pagast, 1936). In dilute solutions of potassium permanganate or silver nitrate, the papillae turn brown and their epidermis is destroyed, while that of the rest of the body is not affected. These results indicate that examination of the anal papillae of aquatic larvae offers another method for study of toxic action.

The fat body has certain of the functions of an organ of excretion, for uric acid and possibly other waste products of metabolism occur in certain cells lying within the fat body. Wigglesworth (1939, p. 318-19) and others have expressed the opinion that this is an example of temporary storage rather than of true elimination, and it is unlikely that interference with this function after the absorption of an insecticide would be of serious consequence. On the other hand, the fat body may play an active role in the removal of toxic substances from the circulating body fluid. Among several tissues of the southern armyworm, Prodenia eridania, tested as deactivators of pyrethrum, Woke (1939) found the fat body to be by far the most active. Pyenson and MacLeod (1936) reported that exposure of mealworm (Tenebrio molitor) pupae to naphthalene vapor or injection of this substance in olive-oil solution led to disintegration of the fat body. Its role with other toxic materials deserves study.

\section{THE NERVOUS AND MUSCULAR SYSTEMS}

The study of the effects of toxic substances upon the nervous system of insects is both hindered and facilitated by the physiological functions peculiar to this system. Since it initiates and carries messages in the form of electrical impulses to and from various parts of the body, the most logical method for study would be to determine how these impulses are altered in intensity, frequency, or other properties. The small size of insect nerves has been a serious obstacle to such work, and only a beginning has been made toward an understanding of conditions in the normal insect. Adrian (1931) has studied the potential changes which occur in the isolated nervous system of Dytiscus marginalis. Pumphrey and Rawdon-Smith (1936) placed fine platinum wires upon the nerves leading from the anal cercus of the cricket, Gryllus domesticus, or the cock- 
roach, Periplaneta americana, and by amplifying the impulses picked up from the nerves they were able to show that these cerci are organs of hearing and respond over the range of frequencies from a single puff of air to 3,000-4,000 vibrations per second. In a later paper (Pumphrey and Rawdon-Smith, 1937) they report detailed study of the response of ganglia of the central nervous system of the cockroach to impulses carried in by the nerves from the cerci. They were able to determine the rate of conduction in the pre- and postganglionic fibers and the length of the synaptic delay. Experiments of this kind offer a method for study of the effects of poisonous substances applied to the body as a whole or to any part desired. On the other hand, the behavior of the muscles is an indication of the kind of nervous impulses which they are receiving, and hence convulsions, vomiting, paralysis, etc., after the application of a poison give information on the state of the nervous system.

In a few cases, it has been found possible to detect cytological changes in the nerves or ganglia. Wilcoxon and Hartzell (1933), for example, made sections of the ventral ganglia and nerve cord of Tenebrio molitor larvae which had been kept in concentrated pyrethrin solution for several hours and found vacuolated regions and areas that stained abnormally with toluidine blue. In a continuation of this work, Hartzell (1934) killed adult grasshoppers and meal worms by applying concentrated pyrethrum solutions to their dorsal surfaces. The brain, subeosophageal ganglion, thoracic ganglia, abdominal ganglia, and connecting nerves all showed degeneration characterized by vacuoles and abnormal staining of the Nissl granules and other parts. For comparison, meal worms were smeared with triorthocresyl phosphate, which is known to cause nerve lesions in higher animals. In the insects, the effects upon the ventral ganglia resembled those caused by pyrethrum. In similar experiments with rotenone, no changes in the nervous tissue could be detected.

F. Krüger (1931) examined the nerves and ganglia of Corethra plumicornis larvae which had been thrown into persistent convulsions in extracts or suspensions of pyrethrum powder. With all but the most dilute solution, he observed a cloudy appearance which under magnification either in the intact insect or in sections showed the nerves and ganglia to be so filled with minute vacuoles that they appeared foamy. The vacuoles are in the nerve fibers and not between them. But with the lowest concentrations which cause convulsions, about $1: 10,000,000$, no vacuoles could be detected. Furthermore, larvae which were first etherized and then placed in pyrethrum suspensions developed vacuoles but did not have convulsions.

Evidence that the characteristic spasms caused by pyrethrum are the 
result of direct action upon the central nervous system is given by experiments in which the material was applied at different distances from the important ganglia. Thus Hartzell and Wilcoxon (1932) found a retardation in the onset of symptoms as pyrethrin was put upon the dorsal region of tomato worms at increasing distances from the head. Similarly, Gösswald (1934) applied a dust containing pyrethrum to Lymantria monacha larvae and found that distress set in very promptly when it was put upon the fore part of the body but more slowly as application was made to the rear portion. The extensive experiments of Klinger (1936) with some twenty species of insects brought out clearly the great variations in sensitivity to pyrethrum. No symptoms were observed, however, which could not be attributed primarily to toxic effects upon the nervous system.

Nicotine has long been known to affect the central nervous system of man and animals, the symptoms indicating an initial stimulation or irritation followed by depression and unconsciousness. The same action appears to occur in insects. It is a common observation that insects become excited immediately after exposure to nicotine and then become motionless after a period depending upon the amount used, the method of application, etc. McIndoo (1916) applied a solution of phosphomolybdic acid to sections including the nerve cord of aphids which had been treated with nicotine and found a precipitate in the ganglia which he thought to be nicotine phosphomolybdate. Recently, he injected known amounts of nicotine, either free or combined, into the abdomen of several species of flies and lepidopterous larvae (McIndoo, 1937). The characteristic sequence of stimulation and subsequent depression with paralysis was noted. In the case of Phormia regina, male flies are more severely affected than females, and maximum resistance occurs at the age of 4 to 6 days. The abrupt variation both before and after this time illustrate the necessity for carefully standardizing insects for toxicity studies. In general, the incidence and persistence of toxic effects were determined by how close the nicotine solution was placed to the ventral ganglion.

McIndoo made a comparison of the relative toxic effects of free nicotine and nicotine sulfate as measured by the time before an injected fly first showed signs of revival and the time before it again was able to stand. By both methods the free nicotine was slightly more effective. This result is in conformity with the greater ease of penetration of cells by molecules and is analogous to the much greater toxicity of nicotine to mosquito larvae at higher $\mathrm{pH}$ (Richardson and Shepard, 1930), as discussed earlier. In McIndoo's work, however, the nicotine solutions were merely 
made acid or alkaline by addition of hydrochloric acid or sodium hydroxide. Therefore they had little buffering power, and very soon after injection they undoubtedly came to the normal $\mathrm{pH}$ of the fly's body fluid and hence but little difference in toxic effects is to be expected.

In the course of a study of the comparative effects of the dextro- and levorotary forms of nicotine upon representatives of the various animal phyla, Gause and Smaragdova (1939) found larvae of Drosophila melanogaster to be equally susceptible to the two isomeric forms. Vertebrates are considerably more sensitive to levonicotine. Among the phyla there is a complete coincidence between a higher toxic effect from levonicotine and the presence in the organism of the acetylcholine system for transmission of nerve impulses. It is not necessarily true that all insects resemble Drosophila in this respect, for acetylcholine may occur in some species (Bacq, 1935).

As may be expected from its close chemical relationship to nicotine, the hydrogenated dipyridyl compound anabasine exerts its principal effects upon the central nervous system. Larvae of the sawfly, Pteronus ribesii, become paralyzed in 2-15 minutes after immersion in a 0.5 per cent solution (Rotman, 1936). The duration of this helpless condition is 8 to 12 hours with young larvae and less with older ones. The accompanying decrease in respiration may be attributed to the effect upon the nervous system.

Organic thiocyanogen compounds, such as propyl thiocyanate $\left(\mathrm{CH}_{3} \mathrm{CH}_{2} \mathrm{CH}_{2} \mathrm{SCN}\right)$ were found by Taubmann (1930) to have a paralytic effect upon both warm- and cold-blooded animals. The interest in such compounds as contact insecticides (see Murphy and Peet, 1932, 1933) makes their mode of action on insects of practical interest. Hartzell and Wilcoxon (1934) prepared fifteen such substances and made a detailed study of the effects of placing a drop of $\gamma$-thiocyanopropyl phenyl ether $\left[\mathrm{C}_{6} \mathrm{H}_{5} \mathrm{O}\left(\mathrm{CH}_{2}\right)_{3} \mathrm{SCN}\right]$ upon the dorsum of a fifth-instar nymph of the cockroach, Periplaneta americana. Twitching of the body and partial paralysis of the posterior legs were noted within a few minutes, and within an hour the legs were completely paralyzed. Death followed in 3 hours. Cytological examination of the abdominal ganglia showed disintégration and vacuolization with abnormal staining reactions. They concluded that destruction of the central nervous system tissue is the primary factor in the toxic effects.

The ingestion of formaldehyde solutions by houseflies causes a progressive paralysis which starts with the abdomen and proceeds to include the posterior, the middle, and anterior legs, in order (Hiestand, 1932). Finally, antennal and proboscis movements cease and paralysis is 
complete. These results are particularly interesting because motions controlled by the cephalic ganglia are the last to disappear. With mammals, on the other hand, the most complex centers are usually affected first.

Very recently (Roeder, 1939) has reported the results of injecting certain substances often used in medicine into the head capsule of praying mantids, Mantis religiosa, and of cockroaches, Periplaneta americana. Strychnine causes a decrease in the reflex activity and complete cessation of mouth part and antennal motion. Since these symptoms may also be produced by destruction of the cerebral ganglia, it may be concluded that toward these insects at least, strychnine entirely lacks the intense stimulating effect which it manifests toward mammals and instead acts as a depressant. On the other hand, injection of pilocarpin leads to great excitement. In vertebrates this drug stimulates the parasympathetic nervous system and hence there is an indication that the nervous system of insects resembles the parasympathetic system of vertebrates.

The effects of toxic substances upon muscles may be manifested as alterations in the structure of cells or fiber bundles, as changes in the reactions concerned with contraction and relaxation, or as changes in surface tension, orientation at cell surfaces, or other interfacial phenomena which may be concerned with muscle action (see Barnes, 1937, p. 306-14). Within 15 minutes after the application of pyrethrin extract to larvae of Corethra plumicornis, F. Krüger (1931) observed formation of vacuoles within the muscle cells. After prolonged cramps, fissures appeared in the muscle fibers and their normal turgid appearance was lost. While considerable progress has been made in unraveling the complex reactions involved in normal invertebrate muscle action (Baldwin, 1937), there seems to be no work from this point of view with insect muscles. This deficiency must be overcome before much progress can be made in studying the effects of insecticides upon muscle chemistry.

\section{REPRODUCTION}

Physiological functions reach their culmination in the phenomena of reproduction, and hence it may be expected that toxic substances will have important effects upon this process in insects. Such is undoubtedly the case, for the literature contains a great many references to decreased egg laying, poor hatching, difficulty in metamorphosis, etc., after exposure to various poisons. Such effects may occur at any stage of the sexual cycle, for example, in egg or sperm formation, fertilization, embryonic development, growth, transformations, and development of sexual organs. 
Unfortunately, too little information on the physiological aspects is available to permit any coördinated account to be given. The following citations will serve to illustrate the types of observations that have been recorded. Exposure of California red scale, Aonidiella aurantii, to sublethal doses of oil causes many of the young to be born dead and a large fraction of these are premature (Ebeling, 1936). Sublethal exposure to naphthalene delays the development of embryos within the eggs of the meal worm, Tenebrio molitor, and the eggs become reddish in color due to some undetermined coloring matter in the mid-intestine of the developing larvae (Pyenson and MacLeod, 1936). Sterility of eggs from a generation which had been exposed to a toxic substance during some immature stage has been noted often. Thus Speyer (1924) found that codling moths from larvae which had eaten any of the ordinary arsenicals mated and laid eggs normally but the latter did not hatch. Kalandadze (1928) made the same observation with several important forest pests, and Kopec (1935) found that the addition of alcohol to the diet of $L y$ mantria dispar larvae resulted in marked decrease in fertility of eggs from the resulting adults, although no histological changes in the sexual organs were observable.

An example of reduction in number of eggs laid is afforded by the observation of Friedericks and Steiner (1930) that adults from larvae of the pine geometrid, Bupalus piniarius, gathered in a forest district to which an arsenical had been applied, laid about half the number of eggs, and the next generation (which was not given any poison) still fell about one fourth below normal. This is an interesting illustration of Janisch's (1927) suggestion that certain pests might be controlled by use of purposely small doses of insecticide which would cause relatively little immediate mortality but would diminish and weaken the next generation so that after a few years of such treatment the species would cease to be economically important. A careful study of the "second generation" or metatoxic effect of sodium arsenite and sodium fluosilicate upon Locusta migratoria and Lymantria dispar showed marked differences in the responses of the insects and in the effects of the poisons upon them (Sazonov and Skrjabina, 1936). Basing their conclusions upon numbers of eggs laid by females surviving sublethal doses and percentage of eggs hatching, these workers calculated that complete mortality of the filial generation would occur if an arsenical killed 20 per cent of the nymphs of Locusta migratoria or if a fluoride killed 50 per cent. With Lymantria dispar, the direct kill would have to be at least 75 per cent with either poison. Sazonov and Skrjabina call attention to the great differences in amount of poison consumed as the result of practical control work and 
conclude that small dosages are not practical for the two insects they used. Since their work was done only with females, which were paired with normal males, it is doubtless true that somewhat greater mortality of the filial generation would be secured from a given dosage of poison under conditions in which both sexes were exposed. However, there are sexual differences in the effects upon reproduction, for Sinitsky and Zalkind (1934), who studied the metatoxic effects of sodium fluosilicate upon the sugar-beet webworm, Loxostege sticticalis, found that exposure of males to the poison had less effect upon reproduction than did exposure of females.

In a detailed study of how pyrethrum affects the larvae of several of the important forest insects of Europe, Gösswald (1934) found that in the case of those which spend but a short time in the pupal state, such as Lymantria monacha, L. dispar, Euproctis chrysorrhoea, mortality of the pupae from surviving larvae was normal; but in the case of Bupalus piniarius, which passes the winter as a pupa, the mortality of this stage was much higher. With all the species, he found that adults from surviving larvae laid fewer eggs than normal.

In none of the studies mentioned above was any attempt made to determine the underlying histological, biochemical, or physiological processes responsible for the abnormal symptoms observed. Obviously a rich field awaits investigation.

\section{ACKNOWLEDGMENTS}

Grateful acknowledgment is hereby given to Dr. Roderick Craig and to numerous graduate students of the Division of Entomology who critically examined the preliminary manuscript during the meetings of the seminar in insect toxicology and physiology, January to December, 1939. Many helpful suggestions were also given by Dr. S. B. Freeborn, Dr. A. M. Michelbacher, Dr. W. Ebeling, Dr. A. M. Boyce, and Dr. D. L. Lindgren. The assistance of translators, research assistants, and typists of the local Works Progress Administration Project No. 665-08-3-29, Unit B-9, has been of great value. 
AdRIAN, E. D.

\section{LITERATURE CITED}

1931. Potential changes in the isolated nervous system of Dytiscus marginalis. Jour. Physiol. $72: 132-51$.

Alexandrov, V. J.

1934. Permeability of the chitin of some dipterous larvae and methods for its investigation. [In Russian.] Biologicheskii Zhurnal 3:490-507.

1935. Permeability of chitin in some dipterous larvae and the method of study. Acta Zoologica 17:1-19.

BABERS, F. H.

1938. An analysis of the blood of the sixth-instar southern armyworm (Prodenia eridania). Jour. Agr. Res. 57:697-706.

BACQ, Z. M.

1935. La transmission chimique des influx dans le système verveux autonome. Ergeb. d. Physiol. 37:82-185.

BALDWIN, E.

1937. An introduction to comparative biochemistry. 112 p. Cambridge University Press, Cambridge, England.

BARNES, T. C.

1937. Textbook of general physiology. 554 p. P. Blakiston's Son \& Co., Inc., Philadelphia, $\dot{\mathrm{P}}$.

Belleuvre, G.

1938. Action physiologique des pyrethrins sur les invertebrates. Anns. de Physiol. et Physicochim. Biol. 14:717-33.

BERAN, F.

1939. Die Wirkungsweise von Obstbaumkarbolineumemulsionen mit besonderer Berücksichtigung der Anwendungstemperatur. Nachrichtenbl. f. den Deut. Pflanzenschutzdienst $4: 1-4$.

BergMaNN, W.

1938. The composition of ether extractives from exuviae of the silkworm, Bombyx mori. Ent. Soc. Amer. Ann. 31:315-21.

BODINE, J. H.

1934. The effect of cyanide on the oxygen consumption of normal and blocked embryonic cells (Orthoptera). Jour. Cell. and Compar. Physiol. 4 : $397-404$.

Bodine, J. H., and E. J. BoEll.

1934. Respiratory mechanisms of normally developing and blocked embryonic cells (Orthoptera). Jour. Cell. and Compar. Physiol. 5:97-113.

Brown, A. W. A.

1937. Studies on the excreta of a grasshopper (Melanoplus bivittatus Say). Jour. Exp. Biol. 14:87-94.

BUChMANN, W.

1931. Untersuchungen über die Bedeutung der Wasserstoffionkonzentration für die Entwicklung der Mückenlarven. Ztschr. f. Angew. Ent. 18:404-17.

1933. Untersuchungen über die Teilchengrösse der wirksamen Substanz von wässrigen Pyrethrum Insektenpulver Suspensionen. Ztschr. f. Angew. Ent. 20 : $136-49$. 
Buxton, P. A.

1932. The relation of adult Rhodnius prolixus (Reuvidae, Rhynchota) to atmospheric humidity. Parasitology 24:429-39.

CAMPBeld, F. L.

1926. Effects of trivalent and pentavalent arsenic on heart pulsations of the silkworm. Jour. Pharmacol. and Exp. Ther. 26:277-85.

1929. The detection and estimation of insect chitin ; and the irrelation of "chitinization" to hardness and pigmentation of the cuticula of the American cockroach, Periplaneta americana L. Ent. Soc. Amer. Ann. 22:401-26.

CAmpbell, F. L., and C. Lukens.

1931. A radioactive indicator method for estimating the solubility of acid lead arsenate within the alimentary tract of the silkworm. Jour. Econ. Ent. 24: $88-94$.

CARPenter, E. L., and W. Moore.

1938. Sorption of hydrocyanic acid by different species of insects. Jour. Econ. Ent. 31:270-75.

CARTER, R. H.

1931. The incompatibility of lime with fluosilicates. Jour. Econ. Ent. 24:263-68.

Chibnall, A. C., S. H. Piper, A. Pollard, E. F. Williams, and P. N. Sahai.

1934. The constitution of the primary alcohols, fatty acids and paraffins present in plant and insect waxes. Biochem. Jour. 28:2187-2208.

Cook, F. C., and N. E. McIndoo.

1924. Chemical, physical and insecticidal properties of arsenicals. U. S. Dept. Agr. Dept. Bul. $1147: 1-57$.

Cook, S. F.

1932. The respiratory gas exchange in Termopsis nevadensis. Biol. Bul. 53:24657.

Corbett, G. H., and E. P. Hodgkin.

1931. Laboratory experiments on the larvicidal properties of mineral oils. Bul. Inst. Med. Res., Fed. Malay States 5:1-20.

Cotron, R. T.

1932. The relation of respiratory metabolism of insects to their susceptibility to fumigants. Jour. Econ. Ent. 25:1088-1103.

Cotton, R. T., G. B. W AGNER, and H. D. Young.

1937. Oxygen as a factor in vacuum fumigation. Jour. Econ. Ent. 30:560.

Cotton, R. T., and H. D. Young.

1929. The use of carbon dioxide to increase the insecticidal efficacy of fumigants. Ent. Soc. Wash. Proc. 31:97-102.

Craig, R., and C. Wilson.

1937. The use of buffered solutions in staining: theory and practice. Stain Technol. 12:99-109.

Cupples, H. L., H. R. Yust, and J. Hiley.

1936. Tests of possible substitutes for hydrocyanic acid in fumigation of California red scale. Jour. Econ. Ent. 29:611-18.

DEBuck, A.

1937. Some observations on the salivary and stomach secretions of Anopheles and other mosquitoes. K. Akad. van Wetensch. te Amsterdam, Afd. Natuurk., Proc., Sect. Sci. 40:217-23. 
Dehn, Madeline von.

1933. Untersuchungen über die Bildung der peritrophischen Membran bei den Insekten. Ztschr. f. Zellforsch. u. Mikros. Anat. 19:79-105.

Demjanowski, S., R. Galzowa, and W. Roshdestwenska.

1932. Wahre Azidität der Hämolymph von Bombyx mori L. 1. Mitteilung: Zur Kenntnis des Stoff wechsels der Seidenraupen. Biochem. Ztschr. 247:386485 .

DeOng, E. R., H. Knight, and J. C. Chamberlin.

1927. A preliminary study of petroleum oil as an insecticide for citrus trees. Hilgardia 2(9) :351-84.

\section{Dodonov, V.}

1936. On the comparative resistance of some species of insects to the arsenic and fluorine insecticides. [In Russian.] Zashch. Rast. ot Ured. (Plant Protect.) Ser. III. 7:55-74.

Duspiva, F.

1936. Beitrïge zur enzymatischem Histochemie. XXI. Die proteolytischen Enzyme der Kleider- und Wachsmottenraupen. Ztschr. f. Physiol. Chem. 241: 177-200.

EBeLing, W.

1936. Effect of oil spray on California red scale at various stages of development. Hilgardia $10(4): 95-125$.

ElLisor, L. O., and C. H. Richardson.

1938. Penetration of nicotine into the goldfish from solutions of various hydrogen ion concentrations. Jour. Cell. and Compar. Physiol. 11:377-87.

Evans, A. C., and H. Martin.

1935. The incorporation of direct with protective insecticides and fungicides. 1. The laboratory evaluation of water-soluble wetting agents as constituents of combined washes. Jour. Pomol. and Hort. Sci. 13:261-92.

Fire, J. M.

1932. A method of artificially feeding the sugar-beet leafhopper. Science 75:46566.

Fife, J. M., and V. L. Frampton.

1936. The $\mathrm{pH}$ gradient extending from the phloem into the parenchyma of the sugar beet and its relation to the feeding behavior of Eutettix tenellus. Jour. Agr. Res. 53:581-93.

Fink, D. E.

1926. Physiological studies of effect of arsenicals on the respiratory metabolism of insects. Jour. Agr. Res. 33:993-1007.

1927. Is glutathione the arsenic receptor in insects? Jour. Econ. Ent. 20:794-801.

1932. The digestive enzymes of the Colorado potato beetle and the influence of arsenicals on their activity. Jour. Agr. Res. 45:471-82.

Fisher, R. A.

1935. The effect of acetic acid vapor treatment on blood cell counts in the cockroach, Blatta orientalis L. Ent. Soc. Amer. Ann. 28:146-53.

1936. The effect of a few toxic substances upon the total blood cell count in the cockroach, Blatta orientalis L. Ent. Soc. Amer. Ann. 29:335-40.

Friedericks, K., and P. Steiner.

1930. Über Nachwirkungen der Begiftung des Kiefernspanners. Ztschr. f. Angew. Ent. 16:189-96. 
Fulmek, L.

1929. Giftigkeitsunterschiede gebraüchlicher Arsenmittel. Fortschr. der Landw. $4: 209-12$.

GäBLER, H.

1939. Das Eindringvermögen verschiedener Flüssigkeiten in die Tracheen und seine Folgen. Ztschr. f. Angew. Ent. 26:1-62.

Gause, G. F., and N. P. Smaragdova.

1939. On the killing action of optically isomeric nicotines in relation to problems of evolution of the nervous system in animals. Physiol. Zool. 12:238-55.

GEROULD, J. H.

1933. Orders of insects with heart-beat reversal. Biol. Bul. 64:424-31.

GöRNITZ, K.

1933a. Pathologische Veränderungen bei $V$ anessa io nach Aufnahme von Arsenverbindungen. Anz. f. Schädlingsk. 9:40-41.

1933b. Methoden zur Prüfung von Pflanzenschutzmitteln. IV. Neue Apparate und Methoden. Mitt. aus der Biol. Reichsanst. f. Land- u. Forstw. 46:1-59.

GössWALD, K.

1934. Die Wirkung des Kontaktgiftes Pyrethrum auf Forstschädlinge unter dem Einfluss der physiologischen Disposition der Schädlinge und der Einwirkung von ökologischen Aussenfaktoren. Ztschr. f. Angew. Ent. 20:489-530.

Granovsky, A. A.

1926. The control of grasshoppers by airplane dusting. Jour. Econ. Ent. 19:79195.

Gray, G. P., and A. F. KirkPatrick.

1929. The protective stupefaction of certain scale insects by hydrocyanic acid vapor. Jour. Econ. Ent. $22: 878-92$.

Guignon, G.

1936. Etude de la circulation sanguine des ailes chez les Coleoptéres et les Orthoptéres au moyen de la nicotine. Compt. Rend. Acad. Sci. [Paris] 202:2105-6.

HAAG, H. B.

1931. Toxicological studies of Derris elliptica and its constituents. 1. Rotenone. Jour. Pharmacol. and Exp. Ther. 43:193-208.

HAAS, A. R. C.

1934. Relation between the chemical composition of citrus scale insects and their resistance to hydrocyanic acid fumigation. Jour. Agr. Res. 49:477-92.

HACKER, H. P.

1925. How oil kills anopheline larvae. Fed. Malay States Malaria Bur. Repts. $111: 1-62$.

HaLdane, J. B. S.

1930. Enzymes. 235 p. Longmans, Green and Co., London.

HaMiLTON, A. G.

1937. The mechanism of respiration of locusts and its bearing on the problem of inhalation of poison dusts. Bul. Ent. Res. 28:53-68.

HaMiLTON, H. L.

1939. Action of acetylcholine, atropine and nicotine on the heart of the grasshopper (Melanoplus differentialis). Jour. Cell. Compar. Physiol. 13:91-103.

HANSBERry, T. R., and C. H. Richardson.

1936. Toxicity of certain stomach poisons to several common lepidopterous larvae. Jour. Econ. Ent. $29: 1160-66$. 
Hartzell, A.

1934. Histopathology of insect nerve lesions caused by insecticides. Boyce Thompson Inst. Contrib. 6:211-23.

HARTZELL, $\Lambda$., and F. Wilcoxon.

1932. Some factors affecting the efficiency of contact insecticides. II. Chemical and toxicological studies of pyrethrum. Boyce Thompson Inst. Contrib. 4: 107-17.

1934. Organic thiocyanogen compounds as insecticides. Boyce Thompson Inst. Contrib. 6:269-77.

Hastings, E. B., and J. H. Pepper.

1939. Studies on some of the factors involved in the use of sodium arsenite against the Mormon cricket (Anabrus simplex Hald.). Montana Agr. Exp. Sta. Bul. $370: 1-26$.

HAZELHOFF, E. H.

1928. Carbon dioxide a chemical accelerating the penetration of respiratory insecticides into the tracheal system by keeping the valves open. Jour. Econ. Ent. $21: 790$.

Hiestand, W. A.

1932. Progressive paralysis of the nervous system of houseflies by formaldehyde and anesthetics. Indiana Acad. Sci. Proc. 41:433-37.

HoBson, R. P.

1931. Studies on the nutrition of blowfly larvae. 1. Structure and function of the alimentary tract. Jour. Exp. Biol. 8:109-23.

Hockenyos, G. L.

1933. The mechanism of absorption of sodium fluoride by roaches. Jour. Econ. Ent. $26: 1162-69$.

1936. Mechanism of absorption of pyrethrum powder by roaches. Jour. Econ. Ent. $29: 433-37$.

1939. Factors influencing the absorption of sodium fluoride by the American cockroach. Jour. Econ. Ent. 32:843-8.

Hoskins, W. M.

1932. Toxicity and permeability. I. The toxicity of acid and basic solutions of sodium arsenite to mosquito pupae. Jour. Econ. Ent. 25:1212-24.

1933. The penetration of insecticidal oils into porous solids. Hilgardia 8(2): 49-82.

Hoskins, W. M., and Y. Ben-Амотz.

1938. The deposit of aqueous solutions and of oil sprays. Hilgardia 12:83-111.

Hoskins, W. M., and R. Craig.

1935. Recent progress in insect physiology. Physiol. Revs. 15:525-96.

Hoskins, W. M., and A. S. HaRRison.

1934. The buffering power of the contents of the ventriculus of the honeybee and its effect upon the toxicity of arsenic. Jour. Econ. Ent. 28:924-42.

HovgH, W. S.

1934. Colorado and Virginia strains of codling moth in relation to their ability to enter sprayed and unsprayed apples. Jour. Agr. Res. 48:533-53.

Ivanova, P. G.

1936. The permeability of the integument of insects to anabasine. [In Russian.] Izv. Kurs. Prikl. Zool. 6(3):25-32. 
JAHN, T. L.

1935a. The nature and permeability of the grasshopper egg membranes. I. The EMF across membranes during early diapause. Jour. Cell. and Compar. Physiol. $7: 23-46$.

1935b. Nature and permeability of grasshopper egg membranes. II. Chemical composition of membranes. Soc. Exp. Biol. and Med. Proc. $33: 159-63$.

JANISCH, E.

1927. Das Exponentialgesetz als Grundlage einer vergleichenden Biologie. 383 p. Verlag Springer, Berlin.

JONES, R. M.

1938. Toxicity of fumigant- $\mathrm{CO}_{2}$ mixtures to the red flour beetle. Jour. Econ. Ent. $31: 298-309$.

KALANDADZE, L.

1928. Die Wirkung von Arsenpreparaten auf die wichtigsten Forstschädlinge. Ztschr. f. Angew. Ent. 13:1-96.

KeILIN, D.

1929. Cytochrome and respiratory enzymes. Roy. Soc. London, Proc., Ser. B. 104: $206-52$.

KING, H. H.

1934. The destruction of locusts in flight by means of a poison dust (sodium arsenite) delivered from aireraft. 3d Internatl. Locust Conf. Proc. p. 97-110.

KING, H. H., and W. RutLEDGE.

1932. The use of poison dusts against adult Locusta migratorioides Reh. and Frm. in the Sudan. Bul. Ent. Res. 23:65-68.

KIRSCHNER, $R$.

1932. Beurteilung der Giftwirkung gasformiger Insecticide auf Grund der Schlagfrequenz des Dorsalgefasses. Ztschr. f. Angew. Ent. 19:544-56.

KITCheL, R. L., and W. M. Hoskins.

1935. Respiratory ventilation in the cockroach in air, in carbon dioxide and in nicotine atmospheres. Jour. Econ. Ent. 28:924-33.

KLINGER, $\mathrm{H}$.

1936. Die Insektizidwirkung von Pyrethrum und Derrisgiften und ihre Abhängigkeit vom insekten Körper. Arb. über Physiol. u. Angew. Ent. 3:49-69, 11551.

KNIGHT, H.

1925. Factors affecting efficiency in fumigation with hydrocyanic acid. Hilgardia $1(3): 35-56$.

KoCH, H. J.

1938. The absorption of chloride ions by the anal papillae of Diptera larvae. Jour. Exp. Biol. 15:152-60.

KocIaN, V., and M. SPACEK.

1934. Die Bestimmung der Wasserstoffionkonzentration der Körperflussigkeiten der Coleopteren. Zool. Jahrb., Abt. Allgem. Zool. u. Physiol. Tiere 54: 180-90.

KoIDsumi, K.

1935. Experimentelle Studien über die Transpiration und den Wärmehaushalt bei Insekten. VII.-XII. Taihoku Imp. Univ. Faculty Sci. and Agr., Mem. 12: 281-380. 
Kono, M.

1932-1933. Chemical studies on coccids of Japan. Agr. Chem. Soc. Japan Jour. 8:1150-60; 9:458-66, 1276-83. [In Japanese.] Abstracted in: Chem. Abs. $27: 1409,4312 ; 28: 2418$.

Kono, M., and R. Maruyama.

1934-1938. Chemical studies on coccids of Japan. Agr. Chem. Soc. Japan Jour. $10: 1228-35 ; 11: 647-58 ; 12: 523-30 ; 13: 177-84,191-99,579-85 ; 14$ : 318-28. [In Japanese.] Abstracted in: Chem. Abs. 29:1168, 6958; $30: 7227 ; 31: 5805,8712 ; 32: 6253$.

KOPEC, S.

1935. The influence of alcohol on development and reproduction in insects. [In Russian.] Trudy po Din. Razv. [Moskua] (Trans. Dyn. Devlpmt.) 10:40311.

KozHANTCHIKOV, J.

1932. Sketches on the heart activity of insects. 1 . The normal pulsation rate of the dorsal vessel of Blatta orientalis $\mathrm{L}$. and the effects of certain factors upon it. [In Russian.] Vred. Selsk. Lesnom. Khoz. Izv. (Leningrad Inst. Control. Farm and Forest Pests) Bul. 2:149-72.

KroGH, A.

$1920 a$. Studien über Tracheenrespiration. II. Über Gasdiffusion in den Tracheen. Pflüger's Arch. f. die Gesam. Physiol. 179:95-112.

$1920 b$. Die Kombination von mechanischer Ventilation mit Gasdiffusion nach Versuchen an Dytiscuslarven. Pflüger's Arch. f. die Gesam. Physiol. 179: 113-20.

KRÜGER, F.

1931. Untersuchungen über die Giftwirkung von dalmatisehen Insektpulver auf die Larven von Corethra plumicornis. Ztschr. f. Angew. Ent. 18:344-53.

KRïGER, P.

1933. Vergleichender Fermentstoff wechsel der niederen Tiere. Ergeb. der Physiol. $35: 538-72$.

KüHNELT, W.

1928a. Ein Beitrag zur Histochemie des Insektenskelettes. Zool. Anz. 75:111-13.

1928b. Über den Bau des Insektenskelettes. Zool. Jahrb., Abt. f. Anat. u. Ontog. Tiere $50: 219-78$.

Lavrov, I. N., and V. N. Paramonova.

1936. Solubility of some salts of stomach insecticides in solutions of different $\mathrm{pH}$.

[In Russian.] Zashch. Rast. of Vred. (Plant Protect.) Ser. III, 7:40-53.

LEPESME, $P$.

1937a. L'action externe des arsenicaux sur le criquet pelerin (Schistocerca gregaria Forsk.). Soc. d'Hist. Nat. de l'Afrique du Nord Bul. 28:88-103.

1937b. De l'action externe des arsenicaux sur les insectes. [Paris] Acad. des Sci. Compt. Rend. 204:717-19.

Lester, H. M. O., and I. Lloyd.

1928. Notes on the process of digestion in tsetse flies. Bul. Ent. Res. 19:39-60.

Linderstr $\emptyset_{\text {M-LANG, K., and F. Duspiva. }}$

1936. Studies on enzymatic histochemistry. XVI. The digestion of keratin by the larvae of the elothes moth. Carlsberg Lab. Compt. Rend. des Trav., Sér. Chim. 21:53-82. 
LINDGREN, D. L.

1935. The respiration of insects in relation to the heating and the fumigation of grain. Minnesota Agr. Exp. Sta. Tech. Bul. 109:1-32.

1938. The stupefaction of red scale, Aonidiella aurantii, by hydrocyanic acid. Hilgardia 11(5):211-25.

Mackie, D. B., and W. B. Carter.

1937. Pest control in rural warehouses and suggested improvements. California State Dept. Agr. Mo. Bul. $26: 275-93$.

Mally, C. W.

1923. Arsenite of soda as a locust poison. So. Africa Dept. Agr. Jour. 6:220-23.

Maloeuf, N. S. R.

1935. The myogenic automatism of the contraction of the heart of insects. Ent. Soc. Amer. Ann. $28: 332-37$.

Mansour, K., and J. J. Mansour-Bek.

1937. On the cellulase and other enzymes of the larvae of Stromatium fulvum Villers (Family Cerambycidae). Enzymologia 4:1-6.

Marshall, J.

1939. The hydrogen ion concentration of the digestive fluids and blood of the eodling moth larvae. Jour. Econ. Ent. 32:838-43.

McGovran, E. R.

1931. A method of measuring tracheal ventilation in insects and some results obtained with grasshoppers. Ent. Soc. Amer. Ann. 24:751-61.

1932. The effect of some gases on the tracheal ventilation of grasshoppers. Jour. Econ. Ent. $25: 271-76$.

McIndoo, N. E.

1916. Effects of nicotine as an insecticide. Jour. Agr. Res. 7:89-122.

1937. Quantitative injection and effects of nicotine in insects. Jour. Agr. Res. 55: 909-22.

Melander, A. L.

1914. Can insects become resistant to sprays? Jour. Econ. Ent. 7:167-73.

Metcalf, C. L., and G. L. Hockenyos.

1930. The nature and formation of scale insect shells. Illinois State Acad. Sci. Trans. 22:166-84.

Ministerio de Agricultura, Argentina.

1936. Memoria de la Comision Central de Investigaciones sobre la Langosta correspondiente al ano 1934. 249 p. Buenos Aires, Argentina.

Montalenti, G.

1932. Gli enzimi e l'assorbimento delle sostanze solubili nell'intestino delle termiti. Arch. Zool. Ital. 16 :859-64.

Moore, W.

1933. Studies of the "resistant" California red scale, Aonidiella aurantii Mask. in California. Jour. Econ. Ent. $26: 1140-61$.

1936. Differences between resistant and nonresistant red scale in California. Jour. Econ. Ent. $29: 65-78$.

Moore, W., and E. L. Carpenter.

1938. The fumigation of insects with hydrocyanic acid: effect of different air pressures. Jour. Econ. Ent. 31:419-26. 
Morozov, S. F.

1935. The penetration of contact insecticides. I. Methods of investigation and general properties of the cuticle with regard to its permeability. [In Russian.] Zashch. Rast. ot Vred. (Plant Protect.) 6:38-58.

Murphy, D. F., and C. H. Peet.

1932. Insecticidal activity of aliphatic thiocyanates. I. Aphis. Jour. Econ. Ent. $25: 123-29$.

1933. Insecticidal activity of aliphatic thiocyanates. II. Mealy bug. Jour. Indus. and Engin. Chem. 25:638-39.

MURRAY, D. R. P.

1936. Mineral oils as mosquito larvicides. Bul. Ent. Res. $27: 289-305$.

NELSON, F. C.

1927. The penetration of a contact oil spray into the breathing system of an insect. Jour. Econ. Ent. $20: 632-35$.

NenJukov, D. V., and A. I. TAREEv.

1928. On the action of sodium arsenite as a stomach poison on the organism Locusta migratoria. [In Russian.] Narodnyi Komissariat Zemledelia, U. S. S. R. Rept. of Work of Lab. for Study of Poisonous Substances 5:63-73.

1931. The nonprotein nitrogen of insect blood: its variation with diet and arsenite poisoning. [In Russian.] Zashch. Rast. ot Vred. (Defense des Plantes) 3: $33-38$.

Nisikawa, Y.

1932. Chemical properties of solutions prepared from the sodium fluosilicate-hydrated lime mixtures with special reference to their toxicity to plants. Kyoto Univ. Col. Agr. Mem. $21: 1-15$.

O'KANE, W. C.

1923. Chemistry in the control of plant enemies. Jour. Indus. and Engin. Chem. 15:911-13.

O'Kane, W. C., and W. C. Baker.

1934. Studies of contact insecticides. VIII. 1. A technique for tracing penetration of petroleum oil in insect eggs. 2. Some determinations of oil penetration into insect eggs. New Hampshire Agr. Exp. Sta. Tech. Bul. 60:1-12.

1935. Studies of contact insecticides. IX. Further determinations of oil penetration into insect eggs. New Hampshire Agr. Exp. Sta. Tech. Bul. 62:1-8.

O'Kane, W. C., and J. G. ConkLIN.

1930. Studies of contact insecticides. II. Lime sulphur in relation to San Jose and oyster shell scales. New Hampshire Agr. Exp. Sta. Tech. Bul. 40:1-15.

O'Kane, W. C., and L. C. GLover.

1935. Studies of contact insecticides. X. Penetration of arsenic into insects. New Hampshire Agr. Exp. Sta. Tech. Bul. 63:1-8.

1936. Studies on contact insecticides. XI. Further determinations of the penetration of arsenic into insects. New Hampshire Agr. Exp. Sta. Tech. Bul. 65: 1-8.

O'Kane, W. C., G. L. Walker, H. G. GuX, and O. J. Smith.

1933. Studies of contact insecticides. VI. Reactions of certain insects to controlled applications of various concentrated chemicals. A new technique for initial appraisal of proposed contact insecticides. New Hampshire Agr. Exp. Sta. Tech. Bul. 54:1-23. 
O'Kane, W. C., W. A. Westgate, and L. C. Glover.

1932. Studies of contact insecticides. V. The performance of certain contact agents on various insects. New Hampshire Agr. Exp. Sta. Tech. Bul. 51: $1-20$.

O'Kane, W. C., W. A. Westgate, L. C. Glover, and P. R. Lowry.

1930. Studies of contact insecticides. I. Surface tension, surface activity and wetting ability as factors in the performance of contact insecticides. New Hampshire Agr. Exp. Sta. Tech. Bul. 39:1-44.

ONGARO, D.

1933. Una paraffina nell' uovo di "Bombyx mori." Ann. Chim. Appl. 23:567-72.

OSTERHOUT, W. J. V.

1933. Permeability in large plant cells and in models. Ergeb. der Physiol. 35:9671021.

Osterhout, W. J. V., S. E. Kamerling, and W. M. StTanley.

1934. Kinetics of penetration. VII. Molecular versus ionic transport. Jour. Gen. Physiol. 17:469-80.

Pagast, G.

1936. Über Bau und Funktion der Analpapillen bei Acdcs aegypti L. Zool. Jahrb. Arb. f. Allg. Zool. u. Physiol. Tiere 56:183-218.

Parfentuev, J. A.

1928. Report of the experimental work of the avio-chemical expedition in 1926.

[In Russian.] Zashch. Rast. ot Vred. (Plant Protect.) 5:161-68.

Parfentejev, J. A., and W. Devrient.

1930. Über die Wirkung des Arsens auf den Gasstoffwechsel bei Insekten. Biochem. Ztschr. 217:368-77.

PatTon, R. P., and R. Craig.

1939. Rates of excretion of certain substances by the larva of the meal worm Tenebrio molitor. Jour. Exp. Zool. 81:437-57.

Pearson, A. M., and C. H. Richardson.

1933. The relative toxicity of trisodium arsenite and arsenious acid to the house fly, Musca domestica. Jour. Econ. Ent. 26:486-93.

Peters, G.

1936. Chemie und Toxikologie der Schädlingsbekämpfung. 120 p. F. Enke, Stuttgart, Germany.

Peters, G., and W. Ganter.

1935. Zur Frage der Abtotung des Kornkäfer mit Bläusaure. Ztschr. f. Angew. Ent. 21:547-59.

Piliat, M.

1935. Histological researches into the action of insecticides on the intestinal tube of insects. Bul. Ent. Res. $26: 165-80$.

1936. A histological study of the toxic effect on the alimentary canal of insects. [In Russian.] Zashch. Rast. ot Vred. (Plant Protect.), Ser. III, 7:79-91.

Portier, $\mathrm{P}$.

1930. Symptomes de l'empoisonnement par la nicotine chez les Lepidopteres. Soc. de Biol. [Paris] Compt. Rend. 105:367-69.

Powers, G. E., and T. J. HeadleE.

1939. How petroleum oil kills certain mosquito eggs. Jour. Econ. Ent. 32:219-22. 
Pratt, F. S., A. F. Swain, and D. N. Eldred.

1931. A study of fumigation problems: "protective stupefaction," its application and limitations. Jour. Econ. Ent. 24:1041-63.

1933. Study of auxiliary gases for increasing the toxicity of hydrocyanic gas. Part I. Studies with ladybird beetles as indices of toxicity. Jour. Econ. Ent. $26: 1031-41$.

1935. Study of auxiliary gases for increasing the toxicity of hydrocyanic gas. Part 2. Studies with citrus-infesting scale insects as indices of toxicity. Jour. Econ. Ent. 28:975-83.

Pumphrey, R. J., and A. F. RAwdon-SMith.

1936. Hearing in insects: the nature of the response of certain receptors to auditory stimuli. Roy. Soc. London Proc., Ser. B, $121: 18-27$.

1937. Synaptic transmission of nervous impulses through the last abdominal ganglion of the cockroach. Roy. Soc. London Proc., Ser. B, 122:106-18.

Pyenson, L., and G. F. MacLeod.

1936. The toxic effects of naphthalene on Bruchus obtectus and Tenebrio molitor in various stages of development. Jour. Agr. Res. 5:705-13.

QUAYLE, H. J.

1916. Are scales becoming resistant to fumigation? Univ. California Jour. Agr. $3: 333-34,358$.

1938. The development of resistance to hydrocyanic acid in certain seale insects. Hilgardia 11(5):183-210.

Quayle, H. J., and P. W. Rohrbaugh.

1934. Temperature and humidity in relation to HCN fumigation for the red scale. Jour. Econ. Ent. 28:1083-95.

RAFFY, A.

1934. Les échanges respiratoires des Lépidoptères. Ann. de Physiol. et Physiochim. Biol. $10: 437-52$.

Ramsay, G. C., and J. A. Carpenter.

1932. An investigation on petroleum oils for malaria control purposes. Rec. Malaria Survey India 3:203-18.

RAMSEy, J. A.

1935. The evaporation of water from the cockroach. Jour. Exp. Biol. 12:373-83.

Richardson, C. H., Louise H. Glover, and L. O. Elilisor.

1934. Penetration of gaseous pyridine, piperidine and nicotine into the bodies of certain insects. Science $80: 76-77$.

Richardson, C. H., and H. H. Shepard.

1930. The effect of hydrogen-ion concentration on the toxicity of nicotine, pyridine and methyl pyrrolidine to mosquito larvae. Jour. Agr. Res. 41:337-48.

RIPPER, W.

1930. Zur Frage des Celluloseabbaus bei der Holzverdauung xylophager Insektenlarven. Ztschr. f. Vergleich. Physiol. 13:314-33.

ROEDER, K. D.

1939. The action of certain drugs on the insect central nervous system. Biol. Bul. $76: 183-89$.

Rotman, M. N.

1936. The effect of anabasine on the gaseous exchange in insects. [In Russian.] Izv. Kurs. Prikl. Zool. 6(3):2-14. 
Sazonov, P., and E. Skrjabina.

1936. The metatoxic effect of stomach insecticides. [In Russian.] Zashch. Rast. ot Vred. (Plant Protect.) 11:72-81.

SchlotTKe, E.

1937a. Untersuchungen über die Verdauungsfermente der Insekten. II. Die Fermente der Laub und Feldheuschrecken und ihre Abhängigkeit von der Lebensweise. Ztschr. f. Vergleich. Physiol. 24:422-50.

1937b. Die Abhängigkeit des Fermentgehalters von der Art der Nahrung. Versuche an Periplaneta orientalis L. Ztschr. f. Vergleich. Physiol. 24 :463-92.

SHAFER, G. D.

1915. How contact insecticides kill. III. Michigan Agr. Exp. Sta. Tech. Bul. 21: $1-67$.

Shepard, H. H., and A. W. Buzicky.

1939. Further studies of methyl bromide as an insect fumigant. Jour. Econ. Ent. $32: 854-59$.

Shepard, H. H., D. L. Lindgren, and E. L. Thomas.

1937. The relative toxicity of insect fumigants. Minnesota Agr. Exp. Sta. Tech. Bul. 120:1-23.

SHINODA, O.

1930. Contributions to the knowledge of intestinal secretion in insects. III. On the digestive enzymes of the silkworm. Jour. Biochem. [Japan] 11:345-67.

Shull, W. E., and P. L. Rice.

1933. A method for temporary inhibition of coagulation in the blood of insects. Jour. Econ. Ent. $26: 1083-89$.

Shuli, W. E., M. K. Riley, and C. H. Richardson.

1932. Some effects of certain toxic gases on the blood of the cockroach, Periplaneta orientalis (Linn.). Jour. Econ. Ent. 25:1070-72.

Sikes, Enid K., and V. B. Wigglesworth.

1931. The hatching of insects from the egg and the appearance of air in the tracheal system. Quart. Jour. Micros. Sci. 74:165-92.

SinitZky, N. U., and M. D. ZALKind.

1934. Studies on the effects of sodium fluoride upon the development and fecundity of the sugar beet webworm, Loxostege sticticalis, in connection with sublethal doses given during the larval stage. [In Russian.] Nauch. Zap. Institut Sakh. Promysh. [Kiev] 10(11-12):176-83.

SkrJabina, E.

1936a. Tissue respiration and its importance for the resistance of insects to arsenic. [In Russian.] Summary of scientific research work for year 1935. Lenin Acad. Agr. Sci., U. S. S. R., Inst. Plant Protect. p. 383-86.

$1936 \mathrm{~b}$. The mechanism of insecticidal action. The $\mathrm{pH}$ of the insect's intestines and blood and its modification on poisoning with arsenic and fluorine compounds. [In Russian.] Zashch. Rast. ot Vred. (Plant Protect.), Series III, 7:9-24.

Slifer, Eleanor H.

1938. The formation and structure of a special water-absorbing area in the membranes covering the grasshopper egg. Quart. Jour. Micros. Sci. 80:437-57.

SмIтH, L. M.

1937. Control of the mealy plum aphid. California Agr. Exp. Sta. Bul. 606:1-34. 
SMITH, R. H.

1938. Microtechnique method of testing oil insecticides on scale insects. Jour. Econ. Ent. 31:632-33.

SNipes, B. T., and O. E. TAuber.

1937. Time required for food passage through the alimentary tract of the cockroach, Periplaneta americana Linn. Ent. Soc. Amer. Ann. $30: 277-84$.

SPEYER, W.

1924. Spritzen und Stäuben mit Arsengiften zur Bekämpfung der Obstmade. Ztschr. f. Angew. Ent. 10:189-210.

STAHN, I.

1928. Über die Atmungsregulation, besonders die Kohlensäureregulation, bei Dixippus morosus and Aeschna grandis. Zool. Jahrb., Abt. f. Allg. Zool. u. Physiol. Tiere $46: 1-86$.

Staniland, L. N., F. Tutin, and C. L. Walton.

1930. Investigations on egg-killing washes at the Long Ashton Research Station. Jour. Pomol. and Hort. Sci. 8:129-52.

Stegemann, F.

1930. Die Flügeldecken der Cicindelinae. Ein Beitrag zur Kenntnis der Insektencuticula. Ztschr. f. Morph. u. ökol. der Tiere 18:1-73.

StellwaAg, F.

1924. Die Benetzungsfähigkeit flüssiger Pflanzenschutzmittel und ihre direkte Messbarkeit nach einem neuen Verfahren. Ztschr. f. Angew. Ent. 10:163-76.

SWINGLe, H. S.

1925. Digestive enzymes of an insect. Ohio Jour. Sci. 25:209-18.

1936. Physiology of insects with reference to their control. Alabama Agr. Exp. Sta. Ann. Rept. $47: 26-27$.

1938. Relative toxicities to insects of acid lead arsenatc, calcium arsenate and magnesium arsenate. Jour. Econ. Ent. 31:430-41.

SWINGLe, M. C.

1931a. Hydrogen ion concentration within the digestive tract of certain insects. Ent. Soc. Amer. Ann. $24: 489-95$.

$1931 b$. The influence of soil acidity on the $\mathrm{pH}$ value of the contents of the digestive tract of Japanese beetle larvae. Ent. Soc. Amer. Ann. 24:496-502.

Tarasova, K. L.

1936. The effect of anabasine on heart activity in insects. [In Russian.] Izv. Kurs. Prikl. Zool. 6(3):15-24.

Tareev, A. I., and D. V. Nenjukov.

1931. Effects of poisons on normal digestion and on the blood of Calliptamus italicus. [In Russian.] Zashch. Rast. ot Vred. (Defense des Plantes) 3: $39-49$.

TAUBER, H.

1935. Activators and inhibitors of enzymes. Ergeb. der Enzymforsch. 4:42-67.

TAUBer, O. E.

1934. The distribution of chitin in an insect. Jour. Morph. 56:51-58.

TAUBManN, G.

1930. Untersuchungen über die Wirkungen organischer Rhodanide. Arch. f. Exp. Path. u. Pharmakol. 150:257-84. 
THORPE, W. H.

1930. The biology of the petroleum fly, Psilopa petrolii Coq. Ent. Soc. London Trans. $78: 331-43$.

TISCHLER, N.

1935. Studies on how derris kills insects. Jour. Econ. Ent. 28:215-20.

TrappmanN, W., and G. Nitsche.

1933. Methoden zur Prüfung von Pflanzenschutzmitteln. V. Beitrage zur Giftwertbestimmung und zur Kenntnis der Giftwirkung von Arsenverbindungen. Mitt. aus der Biol. Reichsanstalt f. Land- u. Forstw. 46:61-89.

UVAROV, B. P.

1928. Insect nutrition and metabolism. A summary of the literature. Ent. Soc. London Trans. $76: 255-343$.

VinogRadskaya, O. H.

1935. Osmotic pressure of hemolymph in Anopheles maculipennis. [In Russian.] Meditsinskaia Parasitologiia 4:377-80.

Voskresenskaya, A.

1936a. Poison penetration through the intestinal wall of insects. [In Russian.] Zashch. Rast. ot Vred. (Plant Protect.) Ser. III, 7:25-36.

1936b. Vomiting as the cause of resistance of insects to arsenical compounds. [In Russian.] Summary of the scientific research work for year 1935. Lenin Acad. Agr. Sci., U. S. S. R., Inst. Plant Protect, p. 380-83.

WARBURG, $\mathrm{O}$.

1927. Über die Wirkung von Kohlenoxyd und Stickoxyd auf Atmung und Gärung. Biochem. Ztschr. $189: 354-80$.

WIGGLESWORTH, V. B.

1929. Digestion in the tsetse fly: a study of structure and function. Parasitology $21: 288-321$.

$1930 a$. A theory of tracheal respiration in insects. Roy. Soc. London Proc., Ser. B. $106: 229-50$.

$1930 b$. The formation of the peritrophic membrane in insects, with special reference to the larvae of mosquitoes. Quart. Jour. Micros. Sci. 73:593-616.

1931. The physiology of excretion in a blood-sucking insect, Rhodnius prolixus. (Hemiptera, Reduviidae). Jour. Exp. Biol. 8:411-51.

1932. On the function of the so-called "rectal glands" of insects. Quart. Jour. Micros. Sci. 75:131-50.

1933a. The function of the anal gills of the mosquito larva. Jour. Exp. Biol. 10: $16-24$.

1933b. The physiology of the cuticle and ecdysis in Rhodnius prolixus (Triatomidae, Hemiptera); with special reference to the function of the oenocytes and of the dermal glands. Quart. Jour. Micros. Sci. 76:269-318.

1934. Insect physiology. 134 p. Methuen \& Co., Ltd., London.

1938a. The regulation of osmotic pressure and chloride concentration in the haemolymph of mosquito larvae. Jour. Exp. Biol. 15:235-47.

$1938 b$. The absorption of fluid from the tracheal system of mosquito larvae at hatching and moulting. Jour. Exp. Biol. $15: 248-54$.

1939. The principles of insect physiology. 434 p. E. P. Dutton and Co., New York, N. Y. 
Wilcoxon, F., and A. HARTEELL.

1931. Some factors affecting the efficiency of contact insecticides. I. Surface forces as related to wetting and tracheal penetration. Boyce Thompson Inst. Contrib. 3:1-12.

1933. Some factors affecting the efficiency of contact insecticides. III. Further chemical and toxicological studies of pyrethrum. Boyce Thompson Inst. Contrib. 5:115-27.

WoKe, P. A.

1938. The biological disposition of rotenone after ingestion by the southern armyworm. Jour. Agr. Res. 57:707-12.

1939. Inactivation of pyrethrum after ingestion by the southern armyworm and during incubation with its tissues. Jour. Agr. Res. 58:289-96.

Wolsky, A.

1938. The effect of carbon monoxide on the oxygen consumption of Drosophila melanogaster pupae. Jour. Exp. Biol. 15:225-34.

Woodworth, C. E.

1938. The reactions of wireworms to arsenicals. Jour. Agr. Res. 57:229-38.

YEAGER, J. F.

1938. Mechanographic method of recording insect cardiac activity, with reference to effect of nicotine on isolated heart preparations of Periplaneta americana. Jour. Agr. Res. $56: 267-76$.

1939. Significance of the presystolic notch in the mechanocardiogram of Periplaneta americana (L.). Ent. Soc. Amer. Ann. 32:44-48.

YEAGER, J. F., and J. B. GaHAN.

1937. Effects of the alkaloid nicotine on the rhythmicity of isolated heart preparations from Periplaneta americana and Prodenia eridania. Jour. Agr. Res. $55: 1-19$.

Yeager, J. F., and Anna Hager.

1934. On the rates of contraction of the isolated heart and Malpighian tube of the insect, Periplaneta orientalis: method. Iowa State Col. Jour. Sci. 8:391-95.

Yeager, J. F., Anna Hager, and J. M. Straley.

1935. Some physiological effects of certain aliphatic thiocyanates on the isolated heart preparation from the roach, Blatta orientalis. Ent. Soc. Amer. Ann. $28: 256-64$.

YEAGER, J. F., and O. E. TAUber.

1932. Determination of total blood volume in the cockroach, Periplaneta fuliginosa, with special reference to method. Ent. Soc. Amer. Ann. 25:315-27.

YoNGE, C. M.

1936. On the nature and permeability of chitin. II. The permeability of the uncalcified chitin lining the foregut of Homarus. Roy. Soc. London Proc., Ser. B. $120: 15-41$. 